\title{
Publication, Citation, Career Development, and Recent Trends: Empirical Evidence for Quantitative Marketing Researchers
}

\author{
Surendra Rajiv $\cdot$ Junhong Chu $\cdot$ Zhiying Jiang
}

Published online: 6 January 2015

(C) Springer Science+Business Media New York 2014

\begin{abstract}
We collect demographic and bibliographic data of all standing marketing faculties from the world's top 150 universities to investigate the composition, research productivity, research impact, and career development of quantitative marketing (QT) scholars, using consumer behavior (CB) researchers as a reference. We find that the field of marketing is very male dominated, and male domination is much more salient in the QT area than in the CB area, but the whole discipline is moving towards a more balanced gender structure. The field is also becoming more international with declining percentage of North Americans. The proportion of non-marketing $\mathrm{PhDs}$ is decreasing, though the absolute number is increasing. In terms of research productivity and citation, after controlling for other factors, QT researchers underperform $\mathrm{CB}$ researchers in annual publications and total publications in most of the years, and they can never catch up with CBs in citations. When it comes to the three career milestones, QTs enjoy some advantage for the first job placement compared to CBs. However, they are less likely to obtain associate promotion. QT researchers are more likely to be promoted to full professorship should they pass the associate promotion. We find that citations do not matter for associate promotion, and surprisingly, neither do they matter much for full professorship promotion.
\end{abstract}

With great sadness, Prof. Surendra Rajiv had passed away.

S. Rajiv

Philind Motion Pictures Private Limited, 1004 B, Hill Grange,

Hiranandani Estate, Thane 400607, India

e-mail: surendra.rajiv@gmail.com

J. Chu $(\square)$

NUS Business School, Singapore, Singapore

e-mail: bizcj@nus.edu.sg

\section{Z. Jiang}

Erasmus University Rotterdam, Rotterdam, The Netherlands

e-mail: jiang@ese.eur.nl
Keywords Quantitative marketing · Consumer behavior . Research productivity $\cdot$ Publication $\cdot$ Citation .

Promotion and tenure $\cdot$ School ranking

\section{Introduction}

Ever since the 1960s, quantitative marketing (QT) researchers have ushered in a new era where marketing decisions could be supported by quantitative methods. From sales response models, conjoint analysis, perceptual maps, and Bass diffusion model to choice models, just to name a few, these widely applied marketing analytics have helped firms enhance business efficiency through better understanding of both consumers and competitors. As a result, right products and services are created and delivered to right consumers. Since the early 1980s, in addition to statistics and operations research techniques, QT researchers have added microeconomics and game theory to their repertoire of analytical tools, thereby transforming marketing management as a discipline from scientific art to artistic science.

Entering the twenty-first century, with the phenomenal progress in computing technology and availability of bulky data, QT researchers are expected to have bigger venues to contribute than ever before. However, before immersing into the excitement of the great opportunities on deck, we believe it is also a good timing to examine how we have arrived here. As Stevenson and Adlia [21] said, "We chart our future clearly and wisely only when we know the path which has led us to the present." Hence, the main purpose of this study is to investigate the development of quantitative marketing as a field defined by its researchers. Through this study, we hope to provide a better understanding and a benchmark that have implications for the future development of individual scholars, business schools, or the field as a whole. 
In this study, we collect data of all standing marketing faculties from the world's 150 top universities till August 2011. These universities had the most publications in the four leading marketing journals - Journal of Marketing Research $(J M R)$, Journal of Consumer Research (JCR), Marketing Science $(M K S)$, and Journal of Marketing $(J M),{ }^{1}$ as well as the marketing section of Management Science (MS). The collected data comprise demographic and bibliographic data of each faculty in the pool as well as citation data of each paper since its publication year. With this rich dataset, we are able to portray the field in multiple dimensions with a long time span from 1980 to 2011. We answer questions such as who we are, where we publish, what our research productivity looks like, what the research impact (citation) is, and how publication and citation affect career development. We focus on describing QT researchers with a reference to consumer behavior (CB) scholars.

We find that marketing as a discipline is quite male dominated with $71.3 \%$ of scholars being male. The male domination is more salient in the QT area than in the CB area: $80.4 \%$ of the QT scholars are male, as compared to $63.0 \%$ of the CB researchers. The marketing researchers also come from different regions. North Americans are the largest group, followed by South Asians, and then by Europeans. The portfolio of marketing researchers is becoming more and more international among young cohorts of graduates. North Americans account for $68.3 \%$ in the 1980 cohort, down to $45.7 \%$ in the 1990 cohort, while Chinese have the fastest gains. In terms of the field of $\mathrm{PhD}$ training, more and more non-marketing major $\mathrm{PhD}$ students are joining the field. However, with the expansion of the entire marketing field, the proportion of nonmarketing major $\mathrm{PhDs}$ is actually decreasing. Hence, worries about the intensified competition due to the inflow of nonmarketing major $\mathrm{PhDs}$ are not well grounded. The average academic age of QT researcher in our dataset is 14.46 years compared with 15.53 years for $\mathrm{CB}$ scholars.

In terms of publications, $76.23 \%$ of papers in the dataset are published in business journals, $11.55 \%$ in the psychology journals and $3.18 \%$ in economic journals. When journals are classified into tier-1, tier-2, and tier-3 journals, they comprise $43.59,29.55$, and $26.86 \%$ of the total publications respectively. Many scholars start to publish quite early in their academic career. Of the QT researchers, $17.5 \%$ managed to have one tier-1 publication before graduation compared with $23.0 \%$ of $\mathrm{CB}$ researchers. For tier-2 papers, the proportion is $11.4 \%$ for QT and $18.8 \%$ for CB researchers respectively.

Many universities have adopted the "publish-or-perish" career paths for their faculty. Top-quality research output is important for a school and its faculty members to gain

\footnotetext{
${ }^{1}$ The four leading marketing journals are well defined among the marketing academia. See Lehmann [6], Tellis et al. [23], McAlister [12], Stremersch et al. [20], and Mittal et al. [14].
}

visibility and esteem among their academic peers. Topquality research output is also pivotal for faculty members to obtain tenure promotion and job security. When it comes to research productivity, an examination of the raw data reveals that the annual new publication of tier-1 papers is humpshaped over academic age since graduation. In the initial years, QT researchers underperform CB researchers, but they can catch up with $\mathrm{CB}$ researchers in annual productivity before tenure evaluation and surpass $\mathrm{CB}$ researchers thereafter. For tier-2 papers, the annual new publications peak at year 6 and level off afterwards. It takes QT researchers, on average, 11 years to catch up with their CB counterpart in total publications. Research productivity is affected by academic age (vintage effect), the affiliated department where a unique set of knowledge is embedded, the $\mathrm{PhD}$ graduating school to signal the initial researcher quality, the potential research capability after graduation, etc. After controlling for all these factors, though annual research productivity is still humpshaped in academic age, it takes 26 years for QTs to surpass CBs in total research output. They can never catch up with $\mathrm{CBs}$ in citation. In addition, along the calendar years, both QT and $\mathrm{CB}$ researchers show an increasing trend of annual research output.

It is well known that the Matthew effect exits in academic research that the most prolific scholars become more productive over their career [13]. In our dataset, the top $1 \%$ most prolific researchers account for over $7 \%$ publications, the top $5 \%$ most prolific ones account for $24 \%$ publications, the top $10 \%$ most prolific ones account for $36 \%$ publications, and the top $20 \%$ most prolific ones account for $55 \%$ publications. We check the evolution of such distribution overtime and find it stays quite stable.

Different tiered publications and citations play different roles in the advancement of three career milestones, viz., job placement, associate promotion, and full promotion. For job placement, as expected, we find that tier-1 publications count the most, followed by tier-2 publications. Everything else being the same, QT candidates tend to be placed in schools 23 positions higher in rank than CBs. A QT candidate with one tier-1 paper is likely to get a placement ranked 17 positions higher than those who do not. For CB candidates, the corresponding advantage brought by a tier- 1 publication is 21 positions. Tiered publications matter more to a $\mathrm{CB}$ job candidate than to a QT candidate. However, tier-3 publications do not help but hurt the initial job placement.

For associate promotion, tier- 1 and tier-2 publications can significantly increase the hazard of promotion, and tier-3 publications decrease CBs' chance to be promoted and have no effect on QTs' promotion. In terms of the magnitude of the impact, one tier-1 publication weighs more than three tier-2 publications. In terms of the recent trend, the hazard of being promoted is decreasing with the calendar year, reflecting the fact that it is becoming more difficult to obtain associate 
promotion. Further, compared with $\mathrm{CB}$ researchers, QT researchers are less likely to be promoted. For full professorship promotion, again tier-1 publications matter most. However, along the calendar years, the hazard to get full professorship promotion is increasing, especially for QT researchers. Thus, relatively speaking, it seems that for $\mathrm{CB}$ scholars the challenge is at the job market, while for QT researchers, it is to obtain the associate promotion. Surprisingly, citations do not have large impact on associate as well as full professorship promotion.

In Section 2, we will elaborate how the data is collected and validated. In Section 3, we provide summary statistics and some descriptive analysis. In Section 4, we formally model research productivity. In Section 5, we model the advancements into the three milestones of a researcher's career life. In Section 6, we end the paper with discussions and implications.

\section{Data Collection}

The data in this paper consist of researcher demographics, publications, and citations. Demographics and publication data were collected between June and August 2011 via the following steps. We first examined the Web of Science to determine the 150 universities ${ }^{2}$ that had the most publications in the four leading marketing journals-Journal of Marketing Research (JMR), Journal of Consumer Research (JCR), Marketing Science (MKS), and Journal of Marketing (JM), ${ }^{3}$ as well as the marketing section of Management Science (MS) between the years 1980 and 2010. These universities collectively accounted for $85 \%$ of the individual articles in these journals. We then visited each university's website to compile a list of all standing tenure-track faculty members in the marketing department (division, unit or group), including those who have not yet published. We revisited the websites on 31 August 2011 to ensure that the faculty list was complete and contained no duplicates. As a further quality assurance, we checked the American Marketing Association's "Who Went Where" survey results from 1997 to 2011 to ensure that all those surveyed from the marketing departments of the top 150 universities were included in the list.

Next, looking at each of the scholars' curriculum vitae (CV) or websites, we collected both biographic and bibliographic data. Biographic data includes gender, country of origin, the university where they obtained their bachelor's degree and their major, the university where they received

\footnotetext{
${ }^{2}$ Of the 150 universities, 111 are in the USA, and the rest are in Europe, Canada, China, Singapore, Korea, Australia, Israel, and New Zealand. Appendix 1 lists the top 50 universities.

3 The four leading marketing journals are well defined among the marketing academia. See Lehmann [6], Tellis et al. [23], McAlister [12], Stremersch et al. [20] and Mittal et al. [14].
}

their master's degree and their major, and the university where they received their doctorate degree and their major. Biographic data also contains the dates at which they obtained their degrees, their detailed job history, the calendar years in which they received their associate and full professorship promotions, and the institutions at which these promotions were obtained. Bibliographic data were recorded of all published and forthcoming papers in peer-reviewed journals published in English up to 31 August 2011, including each article's title, authors, journal, year of publication, volume, issue, start page, and end page. In some cases where the scholars did not have or have an incomplete CV or web publication list (e.g., the first publication appeared 3 years after doctoral graduation or the most recent publication appeared before 2011), the bibliographic data was supplemented by JSTOR, Science Direct, and Google Scholar searches. Further, the number of papers Researcher A coauthored with $\mathrm{B}$ is checked to be the same as that Researcher B coauthored with A to ensure the completeness of publications. We also take measures to ensure there are no duplicates of publications for a researcher. The analysis was limited strictly to journal publications; conference proceedings, books, book chapters, book reviews, editorials, comments, replies, rejoinders, and conference reviews were not included.

We next collected annual citations for each article from the year of publication until 2011 via the Web of Science. If a journal is not included by the Web of Science, we collected the citation data in Scopus. We sum over citations across a scholar's all articles to obtain his/her total citations.

We classify marketing scholars into three types based on their research methods, which is achieved by scrutinizing their publications, publishing journals, working papers and worksin-progress, and stated research interests in their CVs. A similar classification strategy is used in Zamudio et al. [25]. Our data covers 1731 current marketing faculty members, of whom $40.7 \%$ (705) are CBs, $37.5 \%$ (649) are QTs, and $21.8 \%$ (377) are STs. We focus our analysis on the 1354 QT and CB researchers.

\section{Data Summary}

\subsection{Who Are They?}

Marketing as a discipline is quite male dominated, with $71.3 \%$ researchers being male. However, as more and more female researchers join the field, the proportion of the male drops from $89.7 \%$ for the 1980 cohort to $60.9 \%$ for the 2011 cohort. The change in gender composition is more salient among QT researchers: Female QT researchers grow from $2.5 \%$ for the 1980 cohort to $34.8 \%$ for the 2011 cohort. For $\mathrm{CB}$ researchers, the proportion of female researchers increases from 17.2 to $43.5 \%$. Since our data were collected in 2011, 
they reflect the status quo of current faculties. For cohorts 2006-2011, they represent the composition of $\mathrm{PhD}$ graduates in those years as they have not gone through the tenure process, while for cohorts before 2006 , the data only contain those graduates who have survived the tenure process and attritions due to various other factors. The low female ratios for the early cohorts may be due to two reasons: (1) there were fewer female $\mathrm{PhD}$ graduates joining the marketing field, and (2) women were less likely to survive the tenure process or other attrition factors.

The marketing researchers come from different countries (Table 1), primarily North American (45.72\%), South Asian (19.35\%), European countries (12.48\%), and China $(10.78 \%)$. Over the years, the field becomes more international, with more non-North Americans joining the field. North Americans dropped from $72.93 \%$ for the 1980-1984 cohorts to $31.58 \%$ for the 2005-2011 cohorts; South Asians experienced a hump-shaped trend, increasing from $14.66 \%$ for the 1980-1984 cohorts to a peak of nearly $30 \%$ for the 1990 s cohorts, and then going down to $15.33 \%$ for the 2005 2011 cohorts; Europeans peaked in the 2000-2004 cohorts; Chinese have been increasing from negligible numbers to $22.65 \%$; other nationalities (South Korea, Israel, Turkey, Singapore, etc.) are also increasing, albeit at a slower rate.

$\mathrm{CB}$ and QT experienced different trends in their composition by country of origin (Fig. 1a, b). Among CB researchers, North Americans accounted for a much larger share (60\%), and their share declined from 84.51 to $42.86 \%$; South Asians increased from 6.34 to $21.13 \%$ for the 1990-1994 cohorts, and then went down to $8.57 \%$; Chinese experienced the largest increase, from nil to $18.57 \%$; other nationalities went up from 4.23 to $17.62 \%$. Among QT researchers, North Americans only accounted for $30.20 \%$, and their shares went down from $60 \%$ to around $20 \%$ for the 1990s cohorts and leveled off thereafter. South Asians accounted for $27.27 \%$, and their share peaked at $43.40 \%$ for the 1985-1989 cohorts, and gradually declined to around $21 \%$. Chinese scholars witnessed the biggest growth, from nil to $26.43 \%$ for the recent cohorts, with an overall share of $14 \%$.

In terms of fields of $\mathrm{PhD}$ training, $23.1 \%$ of the scholars had a PhD from fields other than marketing such as economics, psychology, statistics, management sciences, operations research, and decision sciences. Although there were more $\mathrm{PhDs}$ from other fields joining the marketing discipline, due to the expansion of the entire marketing field, their share decreased from $38.72 \%$ in the $1980-1984$ cohorts to $23.85 \%$ for the 1985-1989 cohorts. It went up to $27.03 \%$ for the 1995-1999 cohorts, and then went down to $22.12 \%$ for the 2000-2004 cohorts, and further down to $11.90 \%$ in the 2005 2011 cohorts. Hence, the worries held by marketing $\mathrm{PhD}$ candidates about possible competition from candidates outside marketing are not well grounded. The trend of nonmarketing PhDs was similar for $\mathrm{CB}$ and QT areas (Fig. 2), though the decline was steeper for the QT area than the CB area.

Across years, Northwestern, Stanford, Pennsylvania, Duke, Columbia, Carnegie Mellon, Florida, Chicago, UCLA, and MIT are the top 10 universities that jointly granted 35.4\% PhDs. Northwestern, Pennsylvania, Carnegie Mellon, MIT, Purdue, Stanford, UCLA, Chicago, UC Berkeley, and Columbia had the most QT PhDs (41.9 \%) and Northwestern, Stanford, Florida, Duke, UIUC, Columbia, Ohio State, Chicago, Indiana, and Pennsylvania had the most CB PhDs (38.0\%). The researchers obtained their PhDs in different years, spanning from the late 1960s to 2011.

The researchers, on average, had 15.01 years $(\mathrm{SD}=11.80$, median=12) of academic career since $\mathrm{PhD}$ graduation (or since the start of the faculty career, whichever comes earlier). The average academic age was 14.46 years for QTs $(\mathrm{SD}=$ 11.80 , median $=11)$ and 15.53 years for $\mathrm{CBs}(\mathrm{SD}=11.78$, median=13).

\subsection{Where Do They Publish?}

The marketing researchers in our dataset published 24,589 papers (not adjusted for number of coauthors) in 1717 journals across different fields, including business, psychology, economics, and statistics. Business journals account for $76.23 \%$ publications, psychology journals comprise $11.55 \%$ publications, economics journals represent $3.18 \%$ publications, and statistics journals claim $0.95 \%$ publications. The remaining $8.10 \%$ appear in diverse other fields. There are differences in choice of publication outlets across type of researchers. QT researchers publish $82.62 \%$ of their papers in business
Table 1 Distribution (\%) of researchers by country of origin

\begin{tabular}{lllllll}
\hline & North America & South Asia & European & Chinese & Others & Total \\
\hline $1980-1984$ & 72.93 & 14.66 & 6.77 & 0.00 & 5.64 & 100 \\
$1985-1989$ & 59.23 & 24.62 & 7.69 & 1.54 & 6.92 & 100 \\
$1990-1994$ & 42.97 & 28.91 & 11.72 & 5.47 & 10.94 & 100 \\
$1995-1999$ & 44.32 & 27.03 & 13.51 & 4.32 & 10.81 & 100 \\
$2000-2004$ & 35.10 & 17.79 & 18.75 & 14.42 & 13.94 & 100 \\
$2005-2011$ & 31.58 & 15.33 & 14.19 & 22.65 & 16.25 & 100 \\
Total & 45.72 & 19.35 & 12.48 & 10.78 & 11.67 & 0.00 \\
\hline
\end{tabular}


Fig. 1 Distribution of researchers (\%) by country of origin: $\mathrm{CB}$ versus QT

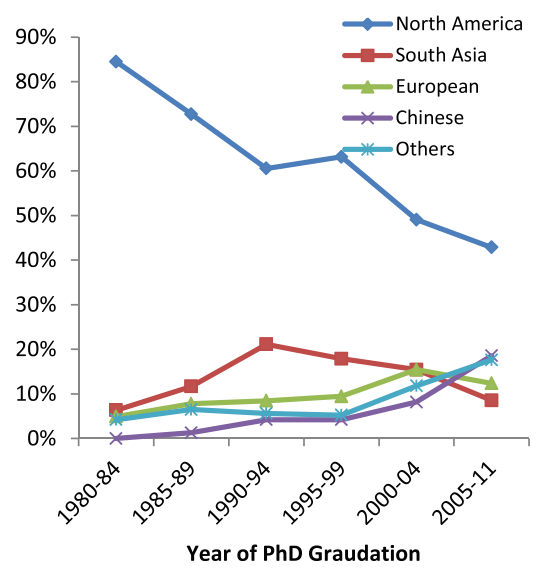

(a) CB Researchers

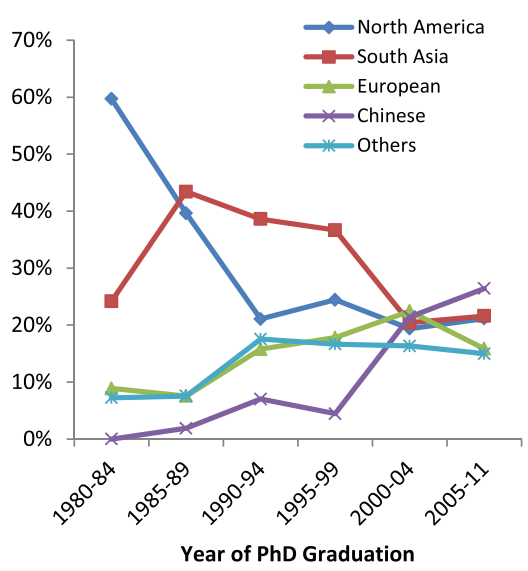

(b) QT Researchers journals, $5.58 \%$ in economics journals, $2.25 \%$ in psychology journals, and $1.81 \%$ in statistics journals. It appears that CB researchers publish more in disciplines other than business: They publish $71.10 \%$ of their papers in business journals, $19.0 \%$ in psychology journals, $1.25 \%$ in economics journals, and $0.26 \%$ in statistics journals.

We classify the publishing outlets into tier-1, tier-2, and tier-3 journals according to the journal tier classification system typically adopted in top-ranked, research-focused universities. There are 164 tier-1 journals, 257 tier-2, and 1296 tier-3 journals, ${ }^{4}$ accounting for, respectively, 43.59, 29.55, and $26.86 \%$ of the total publications. We check the publication portfolio by journal tier for different graduation cohorts (Fig. 3a) and researcher type (Fig. 3b). We found that the proportion of tier-1 publications increases for scholars with shorter academic ages (recent graduates), though tenured scholars still have quite significant proportion of tier-1 publications. QT scholars had higher proportions of tier-1 papers than CB scholars up to 2002 when CBs started to have slightly higher proportions of tier-1 publications. However, the proportions of tier-2 publications of both $\mathrm{CB}$ and QT researchers are quite comparable (the proportions of tier-3 publications for CBs and QTs are not shown in the figure). The top 5 tier- 1 and tier-2 journals for CBs are JCR (14.77\%), JMR (7.96\%), JCP (4.86\%), JM (4.14\%), and JAMS (2.30\%). The top five journals for QTs are MKS (12.94\%), JMR (12.43\%), JM (6.53\%), MS (6.32\%), and IJRM (3.67\%).

\footnotetext{
${ }^{4}$ Appendix 2 lists tier-1 journals in the four primary areas and their shares of publications. These journals coincide well with those in Mittal et al. [14]. Tier-2 marketing journals include Journal of Consumer Psychology (JCP, accounting for $2.91 \%$ publications), International Journal of Research in Marketing (IJRM, $2.29 \%$ publications), Journal of Retailing (JR, $2.35 \%$ publications), Marketing Letters (ML, $2.16 \%$ publications), Journal of the Academy of Marketing Science (JAMS, $1.94 \%$ publications), Journal of Public Policy \& Marketing (JPP\&M, $1.19 \%$ publications), Journal of Advertising ( $J A, 1.22 \%$ publications), Journal of Advertising Research (JAR, $1.00 \%$ publications), Quantitative Marketing and Economics (QME, $0.78 \%$ publications), and International Journal of Retail and Distribution Management (IJRDM, $0.04 \%$ publications).
}

\subsection{When Do They Start Publishing?}

Many marketing researchers start to publish before graduation. In Table 2, we report the percentages of researchers with different numbers of publications as well as mean numbers of publications at different years before $\mathrm{PhD}$ graduation for tier-1 and tier-2 journals. In the year of graduation, $17.5 \%$ of QT students and $23 \%$ of CB students manage to have one tier-1 publication. For tier-2 papers, the portion is $11.4 \%$ for QT and $18.8 \%$ for CB students, respectively. In addition, when comparing the mean number of papers published by QT and $\mathrm{CB}$ students in both tier-1 and tier-2 journals before graduation, CB students easily double the number of publications by QT students across the years before graduation. In this sense, $\mathrm{CB}$ researchers enjoy a head start advantage.

\subsection{How Does the Productivity Look Like in the Career Cycle?}

Levin and Stephan [7] examine research productivity of scientists over the academic life cycle and find that, for the majority of scientists, scientific productivity is investment motivated, not consumption motivated. Research productivity

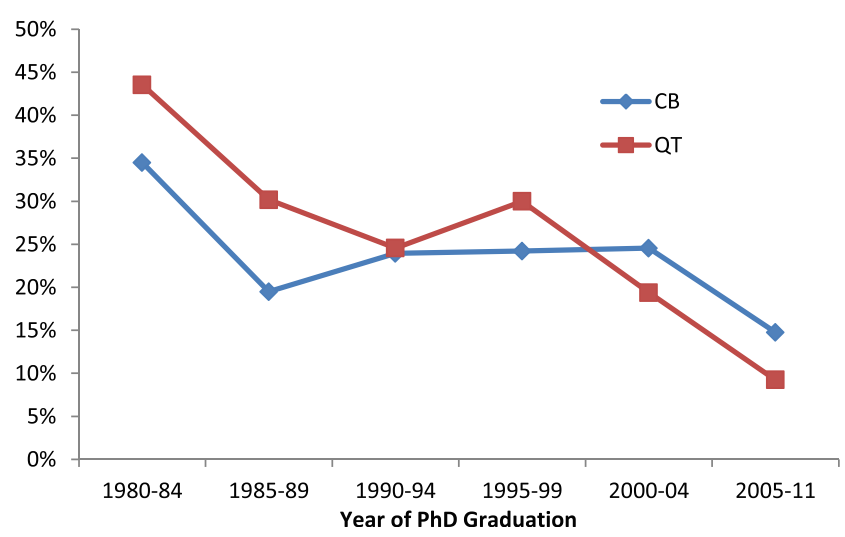

Fig. 2 Percent of non-marketing PhDs by graduation cohort: $\mathrm{CB}$ versus QT 
Fig. 3 a Publications by journal tiers and graduation year. $\mathbf{b}$ Publications by journal tiers: $\mathrm{CB}$ versus QT
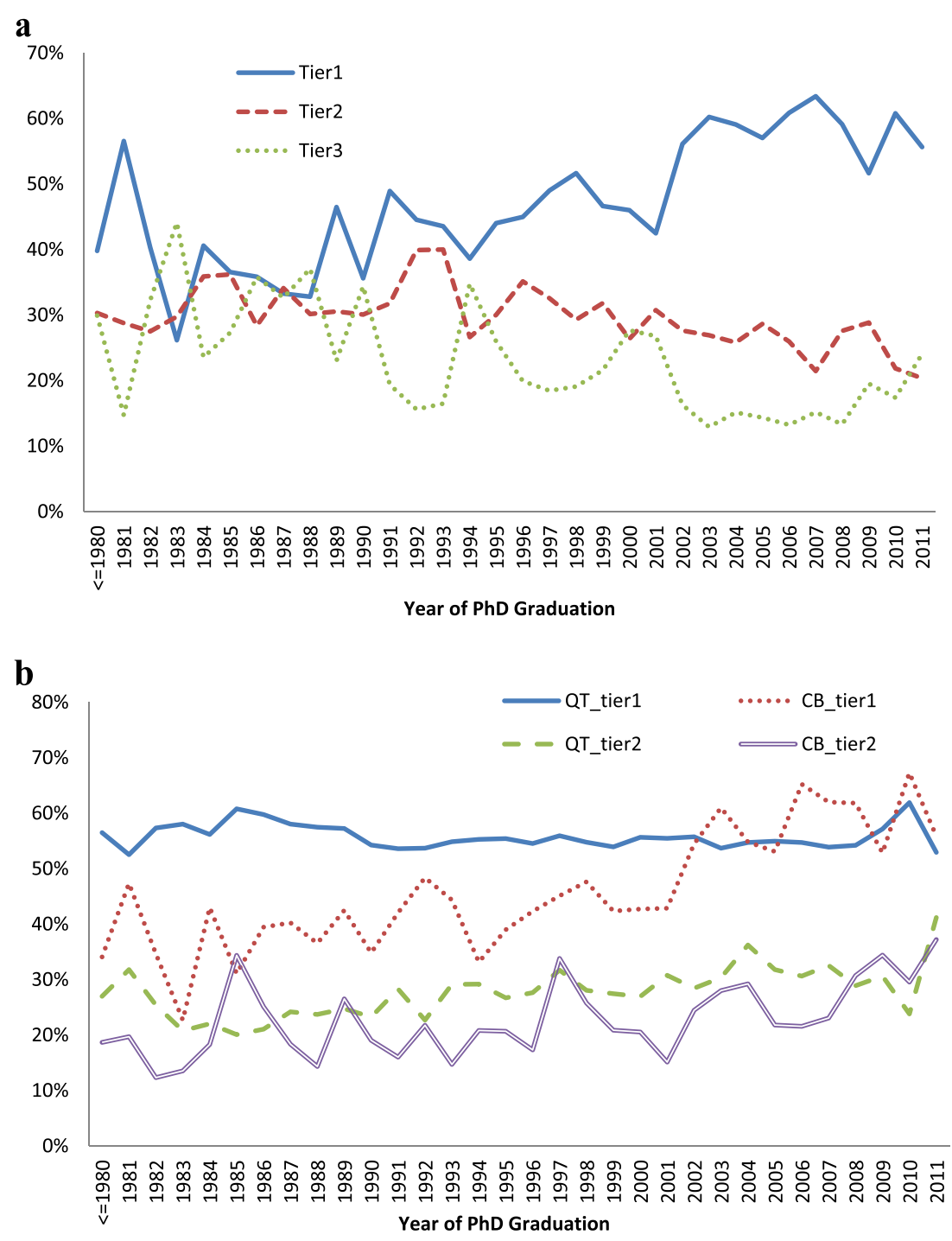

declines over the career. Researchers publish more in the early stage and less in the late stage of their career because the financial rewards from later publications are discounted more than earlier publications.

To check whether publications in marketing follow the same pattern, in Fig. 4a, we plot the annual new publications by academic age, i.e., years since $\mathrm{PhD}$ graduation. Note that the numbers of publications for each academic year are computed based on different cohorts of doctoral graduates: The numbers for year 0 are based on all cohorts, the numbers for year 1 are based on the publications of cohorts up to 2010, the numbers for year 2 are based on the publications of cohorts up to 2009, and so on. Because substantial differences may exist in the nature and quantity of graduates across cohorts, these numbers may not be strictly comparable. Nevertheless, they depict a general picture of research productivity over a scholar's career cycle.

Several observations are in order. First, research productivity in different journal ranks follows different evolution patterns over the academic career cycle. Productivity in tier1 journals is hump-shaped, peaking around year 5 or 6 and declining afterwards, which is consistent with the investment motivation of research as found in Levin and Stephan [7]. A breakdown by researcher type indicates that the hump-shaped productivity pattern holds for QTs and CBs in tier-1 journals. However, research productivity in tier-2 and tier-3 journals increases until year 6 and levels off afterwards, which is more consistent with the consumption motivation of research. Researchers initially have much higher productivity in tier-1 journals than in tier- 2 and tier- 3 journals, reflecting their pursuit of quality research due to the tenure requirements by many schools.

Second, when we split the sample into QT and CB researchers, we found these two streams of researchers follow different evolution paths of annual productivity. In the initial academic years, QT researchers underperform their CB counterparts. Just before tenure evaluation, QT researchers catch up with $\mathrm{CB}$ researchers in terms of new publications in tier-1 
Table 2 Percentage distribution of researchers by number of publications before $\mathrm{PhD}$ graduation

\begin{tabular}{|c|c|c|c|c|c|c|c|c|c|c|c|c|}
\hline \multirow[t]{2}{*}{ Years before $\mathrm{PhD}$} & \multicolumn{6}{|c|}{ CB (all cohorts) } & \multicolumn{6}{|c|}{ QT (all cohorts) } \\
\hline & 0 & 1 & 2 & $3+$ & Mean & $\mathrm{SD}$ & 0 & 1 & 2 & $3+$ & Mean & $\mathrm{SD}$ \\
\hline & \multicolumn{6}{|c|}{ No. of tier-1 publications } & \multicolumn{6}{|c|}{ No. of tier-1 publications } \\
\hline-3 & 93.32 & 4.97 & 1.42 & 0.28 & 0.09 & 0.38 & 97.53 & 2.16 & 0.31 & 0 & 0.03 & 0.18 \\
\hline-2 & 89.02 & 7.51 & 2.6 & 0.87 & 0.16 & 0.55 & 95.64 & 4.05 & 0.31 & 0 & 0.05 & 0.23 \\
\hline-1 & 76.07 & 16.76 & 4.44 & 2.72 & 0.35 & 0.76 & 89.47 & 9.13 & 0.93 & 0.46 & 0.12 & 0.39 \\
\hline \multirow[t]{2}{*}{0} & 61.05 & 22.97 & 10.76 & 5.23 & 0.64 & 1.03 & 78.52 & 17.47 & 2.47 & 1.55 & 0.28 & 0.61 \\
\hline & \multicolumn{6}{|c|}{ No. of tier-2 publications } & \multicolumn{6}{|c|}{ No. of tier-2 publications } \\
\hline-3 & 95.6 & 3.69 & 0.57 & 0.14 & 0.05 & 0.26 & 96.91 & 2.47 & 0.31 & 0.31 & 0.04 & 0.25 \\
\hline-2 & 90.46 & 7.66 & 1.59 & 0.29 & 0.12 & 0.39 & 95.02 & 3.89 & 0.78 & 0.31 & 0.07 & 0.34 \\
\hline-1 & 82.81 & 13.75 & 2.01 & 1.43 & 0.22 & 0.57 & 90.56 & 7.59 & 1.55 & 0.31 & 0.12 & 0.42 \\
\hline \multirow[t]{2}{*}{0} & 74.42 & 18.75 & 4.07 & 2.76 & 0.37 & 0.79 & 84.85 & 11.44 & 3.25 & 0.46 & 0.2 & 0.52 \\
\hline & \multicolumn{6}{|c|}{ No. of tier- 1 and tier- 2 publications } & \multicolumn{6}{|c|}{ No. of tier- 1 and tier-2 publications } \\
\hline-3 & 89.91 & 7.39 & 1.99 & 0.71 & 0.14 & 0.51 & 95.06 & 3.7 & 0.62 & 0.62 & 0.07 & 0.34 \\
\hline-2 & 81.79 & 12.72 & 3.32 & 2.17 & 0.28 & 0.74 & 91.43 & 7.17 & 0.47 & 0.93 & 0.11 & 0.44 \\
\hline-1 & 65.19 & 22.64 & 6.59 & 5.59 & 0.58 & 1.05 & 81.58 & 14.71 & 2.17 & 1.55 & 0.24 & 0.6 \\
\hline 0 & 49.27 & 25.73 & 13.37 & 11.63 & 1.01 & 1.46 & 67.85 & 22.26 & 7.11 & 2.78 & 0.47 & 0.85 \\
\hline
\end{tabular}

Fig. 4 a Mean annual new publications by years since $\mathrm{PhD}$. b Mean annual new tier-1 publications by years since $\mathrm{PhD}$
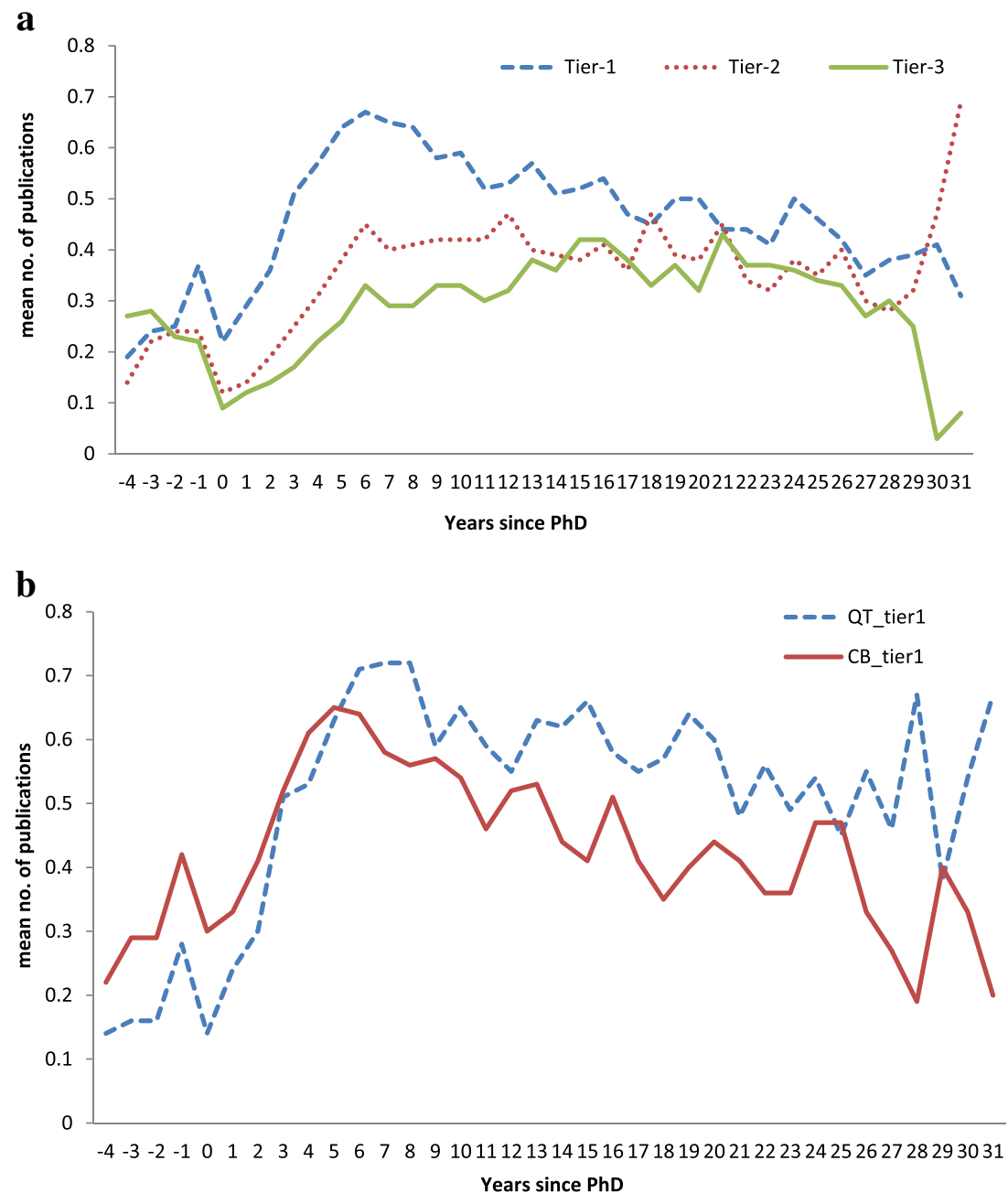
journal (Fig. 4b) and surpass them afterwards. For tier-2 publications, QT researchers also underperform in the initial years and surpass their $\mathrm{CB}$ peers 11 years after graduation. For tier-3 publications, QT researchers always fall below $\mathrm{CB}$ researchers. Note that these are simple averages across researchers of different gender, academic age, PhD school, and job school. As we analyze later, after these factors are accounted for, it takes much longer for QTs to close the publication gaps with CBs.

\subsection{The Skewed Distribution of Research Publications}

The researchers on average have 18.16 publications across all journal ranks, including 7.92 tier-1, 5.37 tier-2, and 4.88 tier-3 publications. There are slight differences across QTs and CBs. CB researchers on average have 19.36 publications across all journals, while QT researchers have 16.86 publications, about 2.5 papers less. QT and CB researchers have the same numbers of tier- 1 and tier-2 publications, but differ in the number of tier-3 publications. A comparison of the numbers of authors and pages per publication across CBs and QTs reveals that tier-1 and tier-2 QT papers are about 1.5 to 2 pages longer, and have slightly less coauthors than $\mathrm{CB}$ papers.

Consistent with the findings in the literature (e.g., $[1,3,11$, 22]), the distribution of publications across researchers is highly skewed. The top $1 \%$ most prolific researchers account for over $7 \%$ publications, the top $5 \%$ most prolific ones account for $24 \%$ publications, the top $10 \%$ most prolific ones account for $36 \%$ publications, and the top $20 \%$ most prolific ones account for $55 \%$ publications. The distribution is stable along the years (Fig. 5). There are no significant differences between CB and QT in the percentile distributions of publications.

\subsection{What is the Research Impact?}

Citations are often used to measure the quality and impact of scientific research. Table 3 reports citations per paper and per researcher by researcher type and gender. Marketing researchers, on average, have 371 citations $(\mathrm{SD}=651)$, 348 for QTs $(\mathrm{SD}=622)$, and 392 for $\mathrm{CBs}(\mathrm{SD}=675)$. The citations are highly skewed among researchers. The median citations are 140, 153 for CBs, and 126 for QTs. There exist large differences in citations of work by male and female researchers. Female researchers have 251 citations in total $(\mathrm{SD}=446)$, and male researchers have 416 citations $(\mathrm{SD}=708), 66 \%$ more than that of female researchers. The median citations of male researchers are 169 , more than double female researchers' median citations (79).

Examining researcher type and gender together, we find that male $\mathrm{CB}$ researchers have the most citations (mean $=453$, $\mathrm{SD}=757$, median $=178$ ), followed by male QT researchers (mean $=383, \mathrm{SD}=659$, median=157). Female QT researchers have the least citations (mean $=178, \mathrm{SD}=352$, median= $43)$. In the mean number of citations, male $C B$ researchers have $60.8 \%$ more than female $\mathrm{CB}$ researchers, $18.3 \%$ more than male QT researchers, and $154.3 \%$ more than female QT researchers; in the median number of citations, male $\mathrm{CB}$ researchers have $74.5 \%$ than female $\mathrm{CB}$ researchers, $13.0 \%$ more than male QT researchers, and $318.8 \%$ more than female QT researchers. Thus, it appears that female QT researchers are most disadvantaged in citations.

A researcher's total citations depend on the number of publications and citations per paper. At paper level, articles by QT researchers, on average, have 34.9 citations $(\mathrm{SD}=$ 103.1), which are $19.2 \%$ less than the citations of papers by $\mathrm{CB}$ researchers (mean $=41.6, \mathrm{SD}=91.0$ ). The citations are highly skewed, and median citations per paper for QTs and CBs are only 15 and 18, respectively. At individual article level, mean citations do not differ much by researcher's gender: Articles by male researchers have slightly higher citations.

Breaking down by researcher's gender and type, we find that papers by male $\mathrm{CB}$ researchers have the highest citations
Fig. 5 Percent of tier 1 publications by top 1,5 , and $10 \%$ most prolific researchers: 1980 2011

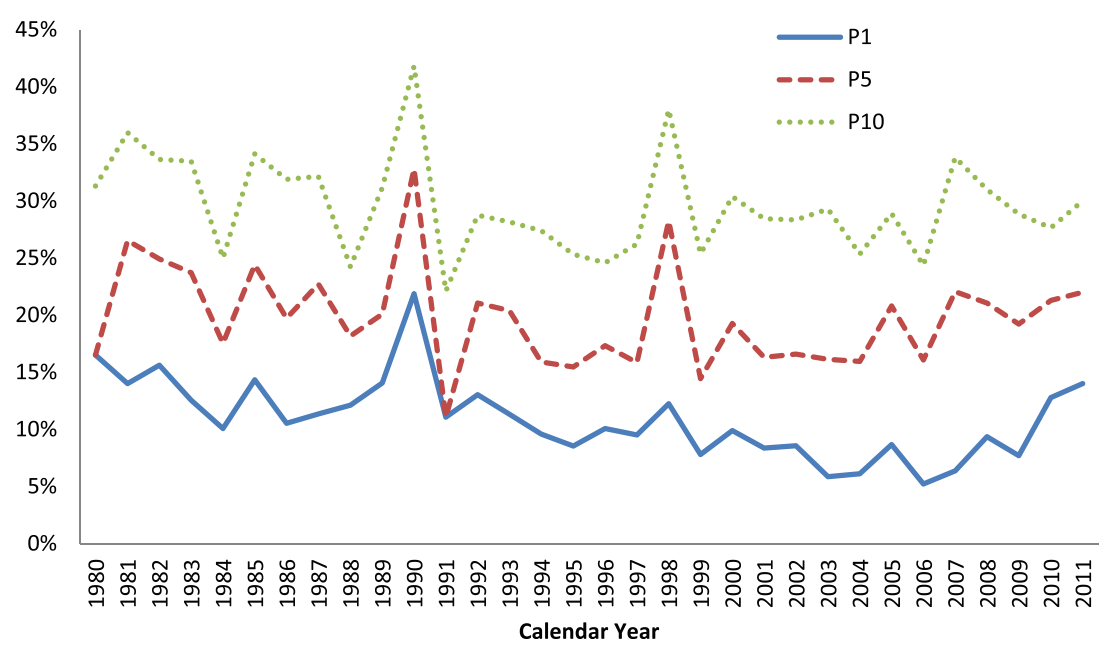


Table 3 Citations by researchers and by paper: CB versus QT

\begin{tabular}{|c|c|c|c|c|c|c|c|c|c|c|c|c|}
\hline & \multicolumn{4}{|l|}{$\mathrm{CB}$} & \multicolumn{4}{|l|}{ QT } & \multicolumn{4}{|l|}{ Total } \\
\hline & Mean & $\mathrm{SD}$ & Median & Max & Mean & $\mathrm{SD}$ & Median & Max & Mean & $\mathrm{SD}$ & Median & Max \\
\hline \multicolumn{13}{|c|}{ Citations per researcher } \\
\hline Female & 281.73 & 477.50 & 102 & 3685 & 178.20 & 351.91 & 42.50 & 2045 & 251.01 & 445.96 & 79 & 3685 \\
\hline Male & 453.15 & 757.26 & 178 & 8014 & 383.03 & 659.22 & 157.50 & 8211 & 416.07 & 707.58 & 168.5 & 8211 \\
\hline Total & 391.87 & 675.42 & 153 & 8014 & 347.59 & 621.70 & 125.50 & 8211 & 371.25 & 651.07 & 140 & 8211 \\
\hline \multicolumn{13}{|c|}{ Citations per paper } \\
\hline Female & 38.41 & 87.65 & 16 & 2446 & 30.79 & 57.57 & 11 & 430 & 40.30 & 101.51 & 15 & 2446 \\
\hline Male & 42.87 & 92.19 & 18 & 2149 & 35.40 & 106.96 & 16 & 5063 & 40.38 & 106.87 & 17 & 5063 \\
\hline Total & 41.63 & 90.97 & 18 & 2446 & 34.94 & 103.07 & 15 & 5063 & 40.36 & 105.86 & 17 & 5063 \\
\hline
\end{tabular}

( mean $=42.9, \mathrm{SD}=92.2$, median $=18$ ), followed by female $\mathrm{CB}$ researchers $($ mean $=38.4, \mathrm{SD}=87.7$, median $=16)$, and male QT researchers (mean $=35.4, \mathrm{SD}=107.0$, medi$\mathrm{an}=16)$. Papers by female QT researchers have the lowest citations $($ mean $=30.8, \mathrm{SD}=57.6$, median=11). Citations depend on publishing journals and paper's age [20]. After controlling for the vintage effect of articles and publishing journals, we find that papers by female researchers actually have more citations than papers by male researchers: papers by female CB researchers have $3.08 \%$ more citations than those by male $\mathrm{CB}$ researchers, while papers by female QT researchers have $31.17 \%$ more citations than those by male QT researchers. This is consistent with the findings in Long [10] that papers by female researchers, on average, receive more citations than those by male researchers.

\section{A Formal Model of Research Productivity and Citation}

\subsection{Research Productivity over the Academic Career}

In terms of research productivity, the above analysis does not account for vintage effect, which arises from the varying knowledge base [7] along a researcher's career progress. Further, research output is also affected by working environment, academic training and other factors like gender [9, 2, 8]. Building on the extant literature in scientometrics (e.g., $[5,19])$, we model research productivity of a scholar as a Poisson distribution as follows ${ }^{5}$ :

$$
\begin{aligned}
& P\left(Q_{i t}=q_{i t}\right)=\frac{e^{-\lambda_{i t}} \lambda_{i t} q_{i t}}{q_{i t} !} \\
& \ln \left(\lambda_{i t}\right)=\beta_{\text {Type } \text { Type }_{i}+\beta_{\text {Type,year }} \text {Type }_{i} * \text { Year }+\beta_{\text {Type }, t} \text { Type }_{i} * t_{i}+\beta_{\text {Type }, \mathrm{g}} \text { Gender }_{i} * \text { Type }_{i}+\beta_{\mathrm{s}} I_{i, \mathrm{st}}+\beta_{\mathrm{PhD}} I_{i, \mathrm{PhD}}}
\end{aligned}
$$

where $\lambda_{i t}$ is the expected number of publications for research $i$ at academic age $t$. $Q_{i t}$ is the number of new or cumulative total publications in tier-1 and tier-2 journals, Type ${ }_{i}$ is researcher type, Year is a dummy for the calendar year, $t_{i}$ is researcher $i$ 's academic age, and Gender ${ }_{i}$ is researcher $i$ 's gender. $I_{i, s t}$ is a dummy for school $s$ that researcher $i$ is affiliated with at $t$. It varies with time because researchers may move from one university to another, and $\beta_{\mathrm{s}}$ captures the school fixed effect, or the environmental effect on research productivity. $I_{i, \mathrm{PhD}}$ is the dummy variable for PhD school and controls for the effect of academic training or research ability on productivity because entering a $\mathrm{PhD}$ program is a highly selective process at the first place. $^{6}$ The exponents of $\beta_{\text {Type, } t}$ capture the vintage effect of academic age on research productivity, revealing how annual new publications or total publications evolve along the career cycle for each researcher type after other factors are controlled for. On the other hand, exponents of $\beta_{\text {Type,year is a vector }}$ measuring how annual publications and cumulative

\footnotetext{
$\overline{{ }^{5} \text { We also tried }}$ to model publications and citations via the negative binomial distribution and obtained similar patterns.

${ }^{6}$ We estimated a model using job school ranks and $\mathrm{PhD}$ school ranks and obtained similar results.
} 
publications evolve over the calendar years. It describes the time trend of researcher's annual and cumulative research productivity.

Table 4 reports the regression coefficients of annual productivity $\beta_{\text {Type,year and }} \beta_{\text {Type, } t}$ based on tier- 1 and tier- 2 publications. Several observations are in order. First, checking the plot of the exponents of the calendar year coefficients in Fig. 6a, we find that, along years, there is a slightly increasing trend of annual publications for CB scholars, and the trend sped up since 2002. For QT scholars, the annual publications

Table 4 Regression of annual publications on years since $\mathrm{PhD}$ graduation

\begin{tabular}{|c|c|c|c|c|c|c|c|c|c|}
\hline \multirow[t]{3}{*}{ Calendar Year } & \multicolumn{4}{|c|}{ Calendar year effect } & \multirow[t]{3}{*}{ Years since $\mathrm{PhD}$} & \multicolumn{4}{|c|}{ vintage effect } \\
\hline & \multicolumn{2}{|l|}{$\mathrm{CB}$} & \multicolumn{2}{|l|}{ QT } & & \multicolumn{2}{|l|}{$\mathrm{CB}$} & \multicolumn{2}{|l|}{ QT } \\
\hline & Est & se & est & se & & est & se & est & $\mathrm{se}$ \\
\hline 1980 & -1.231 & 0.586 & 0.006 & 1.006 & 0 & 0.409 & 0.367 & -1.568 & 0.462 \\
\hline 1981 & -1.108 & 0.385 & 0.324 & 0.417 & 1 & 0.441 & 0.367 & -1.054 & 0.458 \\
\hline 1982 & -0.786 & 0.258 & -0.334 & 0.385 & 2 & 0.650 & 0.365 & -0.791 & 0.457 \\
\hline 1983 & -0.600 & 0.195 & -0.443 & 0.308 & 3 & 0.917 & 0.365 & -0.399 & 0.455 \\
\hline 1984 & -0.953 & 0.197 & -0.237 & 0.226 & 4 & 1.092 & 0.364 & -0.329 & 0.455 \\
\hline 1985 & -1.066 & 0.180 & 0.169 & 0.163 & 5 & 1.156 & 0.364 & -0.112 & 0.455 \\
\hline 1986 & -0.724 & 0.138 & -0.418 & 0.185 & 6 & 1.226 & 0.364 & -0.005 & 0.455 \\
\hline 1987 & -0.915 & 0.141 & -0.125 & 0.143 & 7 & 1.090 & 0.365 & -0.006 & 0.455 \\
\hline 1988 & -0.797 & 0.125 & -0.017 & 0.127 & 8 & 1.023 & 0.365 & 0.021 & 0.455 \\
\hline 1989 & -0.829 & 0.120 & -0.075 & 0.121 & 9 & 1.062 & 0.365 & -0.106 & 0.456 \\
\hline 1990 & -0.540 & 0.102 & -0.120 & 0.117 & 10 & 1.030 & 0.366 & -0.058 & 0.456 \\
\hline 1991 & -0.489 & 0.097 & -0.086 & 0.110 & 11 & 0.949 & 0.366 & -0.155 & 0.456 \\
\hline 1992 & -0.476 & 0.094 & 0.135 & 0.097 & 12 & 1.018 & 0.366 & -0.074 & 0.456 \\
\hline 1993 & -0.619 & 0.096 & -0.111 & 0.102 & 13 & 0.972 & 0.366 & -0.060 & 0.456 \\
\hline 1994 & -0.583 & 0.092 & -0.073 & 0.097 & 14 & 0.865 & 0.367 & -0.105 & 0.457 \\
\hline 1995 & -0.692 & 0.095 & -0.051 & 0.093 & 15 & 0.846 & 0.368 & -0.044 & 0.457 \\
\hline 1996 & -0.622 & 0.090 & -0.190 & 0.094 & 16 & 0.942 & 0.368 & -0.092 & 0.458 \\
\hline 1997 & -0.735 & 0.090 & -0.149 & 0.090 & 17 & 0.691 & 0.370 & -0.142 & 0.459 \\
\hline 1998 & -0.540 & 0.081 & -0.075 & 0.084 & 18 & 0.826 & 0.370 & -0.088 & 0.459 \\
\hline 1999 & -0.481 & 0.078 & -0.116 & 0.082 & 19 & 0.641 & 0.372 & 0.027 & 0.459 \\
\hline 2000 & -0.536 & 0.077 & -0.374 & 0.087 & 20 & 0.768 & 0.371 & -0.143 & 0.461 \\
\hline 2001 & -0.512 & 0.075 & -0.273 & 0.082 & 21 & 0.758 & 0.372 & -0.132 & 0.462 \\
\hline 2002 & -0.593 & 0.075 & -0.207 & 0.078 & 22 & 0.583 & 0.375 & -0.196 & 0.464 \\
\hline 2003 & -0.472 & 0.071 & -0.269 & 0.078 & 23 & 0.454 & 0.377 & -0.279 & 0.465 \\
\hline 2004 & -0.443 & 0.069 & -0.063 & 0.072 & 24 & 0.737 & 0.374 & -0.245 & 0.467 \\
\hline 2005 & -0.386 & 0.067 & -0.085 & 0.071 & 25 & 0.624 & 0.377 & -0.397 & 0.472 \\
\hline 2006 & -0.176 & 0.061 & -0.211 & 0.072 & 26 & 0.474 & 0.383 & -0.253 & 0.473 \\
\hline 2007 & -0.348 & 0.064 & -0.140 & 0.069 & 27 & 0.251 & 0.398 & -0.527 & 0.482 \\
\hline 2008 & -0.203 & 0.060 & -0.044 & 0.066 & 28 & -0.028 & 0.414 & -0.310 & 0.485 \\
\hline 2009 & -0.153 & 0.058 & 0.017 & 0.063 & 29 & 0.327 & 0.408 & -0.648 & 0.515 \\
\hline 2010 & -0.249 & 0.058 & -0.128 & 0.065 & 30 & 0.195 & 0.440 & -0.167 & 0.518 \\
\hline 2011 & 0.000 & 0.000 & 0.000 & 0.000 & $31+$ & 0.000 & 0.000 & 0.000 & 0.000 \\
\hline \multicolumn{10}{|l|}{ Other control variables } \\
\hline \multicolumn{10}{|l|}{ Research type fixed effect } \\
\hline Working school fixed effect & Yes & & & & & & & & \\
\hline $\mathrm{PhD}$ school fixed effect & Yes & & & & & & & & \\
\hline Gender fixed effect & Yes & & & & & & & & \\
\hline $\mathrm{N}$ & 15,512 & & & & & & & & \\
\hline LL & $-13,013$ & & & & & & & & \\
\hline
\end{tabular}


Fig. 6 a Time trend of annual tiered publications: $\mathrm{CB}$ versus QT. b Annual tiered publications by year since $\mathrm{PhD}$ graduation: $\mathrm{CB}$ versus QT
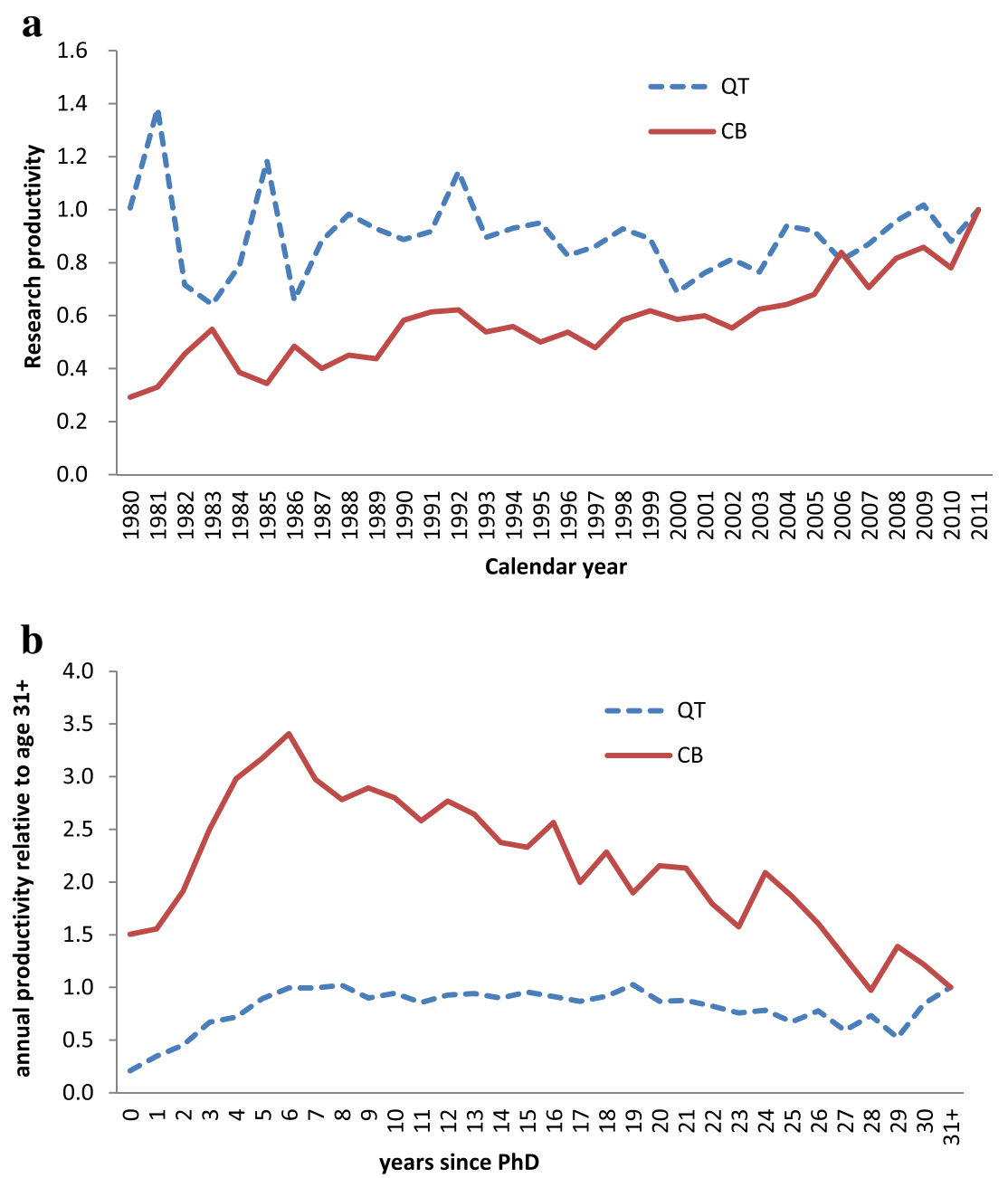

declined from 1980 till 2000 when the trend was reversed towards more publications. Such trends might reflect the common perception that the tenure bar imposed in most schools is rising. However, we see from the data that it is not remarkable. We can also see that QT scholars are producing slightly more over years compared to CB scholars. Such advantage, however, is overshadowed immediately by the vintage effect, as is discussed below.

Figure $6 \mathrm{~b}$ plots the exponents of the coefficients of academic years, which is the vintage effect of annual research productivity, relative to year $31+$, after controlling for other factors such as calendar year period effect, gender, job school, and $\mathrm{PhD}$ school. Annual productivity of both QT and CB scholars is hump-shaped along researcher's career cycle and peaks at year 6, the year of tenure assessment in most of the schools. At the beginning, QT scholars have 1.29 fewer papers than CBs, which is quite close to what is observed from the job market. Then, the gap between QTs and CBs in terms of annual paper production increases and becomes widest at the sixth year. It diminishes thereafter. However, on average, QT scholars produce less than CBs on yearly basis in the whole academic life cycle. Second, a revisit to Fig. 4b suggests QT scholars become more productive after 5 years compared with CBs. However, after controlling for other factors, QTs actually have a lower productivity than CBs in many more years.

Third, there are gender differences in productivity. Compared with male scholars, female scholars are less productive: female QT scholars have $82.4 \%$ of their male counterparts' annual productivity, and female CB scholars have $89.0 \%$ of their male counterparts'. Seggie and Griffith [19] find that gender is not a significant determinant of publication productivity for marketing scholars. Park and Gordon [15] and Williamson and Cable [24] have the same finding in the field of management. Prpic [16] and Rogers and Maranto [17] show that, on average, female scholars are less productive than their male counterparts in science. Our findings indicate a strong interaction effect between gender, researcher type, and tier of publications.

We modeled cumulative tier- 1 and tier- 2 publications on calendar year and years since $\mathrm{PhD}$, controlling for gender, school job, and PhD school fixed effects. Figure 7a depicts the 
Fig. 7 a Time trend of cumulative publication: $\mathrm{CB}$ versus QT. b Cumulative tiered publications by year since $\mathrm{PhD}$ graduation: $\mathrm{CB}$ versus QT
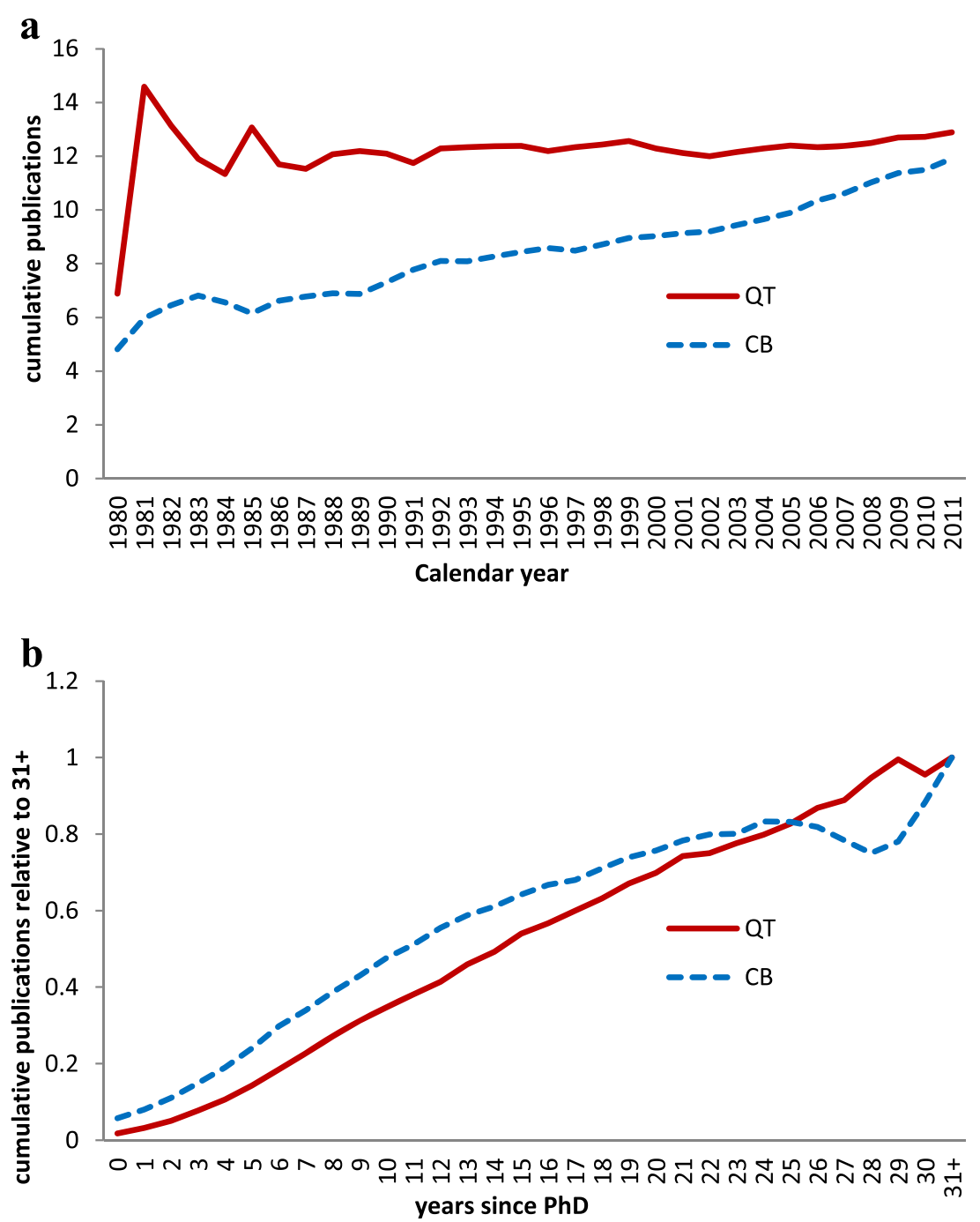

exponents of the calendar year fixed effects or time trend. The cumulative publications for QT scholars are quite stable over the years; however, there is a fast growing trend for CB researchers in cumulative publications, confirming the casual observation in the field.

Figure $7 \mathrm{~b}$ displays the vintage effect of cumulative publications. As expected, total publications grow with academic age. One striking finding is that, after controlling for other factors, it takes 26 years for QTs to surpass $\mathrm{CBS}$ in the total of tier-1 and tier-2 publications, which are much longer than what is shown by the mean cumulative publications based on raw data across these two groups of researchers.

\subsection{Citations over Academic Career}

Similarly, the citation pattern over the academic cycle reported above might be caused by differences across cohorts. We run a Poisson regression of new and cumulative citations as in Eq. (1) (the results are not reported due to space limit). Because QTs publish less and later than CBs, and because papers by QTs on average have fewer citations than papers by $\mathrm{CBs,} \mathrm{QT} \mathrm{researchers} \mathrm{always}$ have fewer citations than their $\mathrm{CB}$ counterparts do, and the QT and CB gaps in citation are much larger than the gaps in publications. There are gender differences both in new and total citations. For $\mathrm{CBs}$, female researchers have $10.7 \%$ lower total citations than male researchers; for QTs, it is the opposite: female researchers have 5.0\% higher citations than male researchers. CBs always have more citations than their QT counterparts do, but the gaps are larger for male researchers than that for female researchers.

\section{Performance Evaluation}

Researchers face various performance evaluations: evaluation by the job market for placement, annual evaluation for merit 
pay raises, midterm evaluation for contract renewal, and tenure or associate promotion, and full professorship promotion. In this section, we examine how publications and citations are treated at three milestones in the academic career, job market placement, associate professorship promotion, and full professorship promotion with other variables controlled.

\subsection{First Job placement}

We use a school's rank as a measure of a school's, actually its marketing department's, academic reputation. Even though we only look at the current faculty in the top 150 universities, their researchers had, at some point in their careers, been part of 291 different universities. We first rank each school according to the total number of articles published by their faculty in $J M R, J C R, M K S, J M$, and the marketing section of $M S$ in the previous 5 years. ${ }^{7}$ The method adopted here is the same as that used by the University of Texas at Dallas to rank business schools. The number of authors in each publication is adjusted by counting each publication as the inverse of the number of authors. The university with the highest number of authorship-adjusted publications was ranked first and so on. When schools tied in their adjusted number of publications, the same rank number was assigned to both schools. The ranks change over time, reflecting the varying fortunes of marketing departments in academia. Due to the stickiness of university
Table 5 Poisson regression of school rank of first job placement

\begin{tabular}{lrrr}
\hline & est & \multicolumn{1}{l}{ se } & \multicolumn{1}{c}{ t-stat } \\
\hline Intercept & 4.974 & 0.028 & 180.221 \\
CB & 0.151 & 0.024 & 6.296 \\
Tier-1 publications & -0.124 & 0.011 & -11.376 \\
Tier-1 publications $\times$ CB & -0.013 & 0.012 & -1.024 \\
Tier-2 publications & -0.108 & 0.011 & -9.575 \\
Tier-2 publications $\times$ CB & -0.072 & 0.014 & -5.294 \\
Tier-3 publications & 0.043 & 0.009 & 5.000 \\
Tier-3 publications $\times$ CB & 0.036 & 0.009 & 3.860 \\
CB $\times$ female & 0.001 & 0.010 & 0.078 \\
QT $\times$ female & -0.009 & 0.013 & -0.652 \\
Other control variables & & & \\
PhD school fixed effects & Yes & & \\
Graduation year fixed effects & Yes & & \\
$N$ & 1354 & & \\
\hline
\end{tabular}

A smaller number of school ranks indicates a more reputable school; thus, a negative coefficient indicates positive impact on job placement

rankings [4], the ranks of schools do not change dramatically in a short period, but they do change remarkably over a long time. $^{8}$

To check how various factors affect the placement of a particular candidate, we run the following regression:

$$
\begin{aligned}
& P\left(R_{i t}=r_{i t}\right)=\frac{e^{-\lambda_{i t}} \lambda_{i t}^{{ }^{r}}{ }{ }_{i t}}{r_{i t} !} \\
& \ln \left(\lambda_{i t}\right)=\beta_{\text {Type } \text { Type }_{i}}+\beta_{\text {type }, 1_{1} \text { Type }_{i}} * \text { Pub }_{i 0}+\beta_{\text {type }, 2^{2} \text { Type }_{i}} * \text { Pub }_{i 0}+\beta_{\text {type }, 3} \text { Type }_{i} * \text { Pub3 }_{i 0} \\
& +\beta_{\text {Type }, \mathrm{g} \text { Gender }_{i}} * \text { Type }_{i}+\beta_{1} I_{i, t}+\beta_{2} I_{i, \mathrm{PhD}}
\end{aligned}
$$

where $R_{i t}$ is the school rank of researcher $i$ 's initial placement in calendar year $t, \operatorname{Pub} 1_{i 0}, \operatorname{Pub} 2_{i 0}$, and Pub $3_{i 0}$ are, respectively, total tier-1, tier-2, and tier-3 publications upon graduation (academic age $=0$ ), and $I_{i, t}$ is the calendar year dummy. The results are in Table 5. Note that a smaller number of school rank indicates a more reputable school; thus, a negative coefficient means positive impact on job placement.

Everything else being the same, i.e., same numbers of different tiered publications, same $\mathrm{PhD}$ school, same graduation year, etc., $\mathrm{CB}$ candidates tend to be placed in schools 23 positions

\footnotetext{
$\overline{7}$ The rankings are based on publications in these five journals by a school's all faculty members, including those who were not included in our data because they were no longer standing faculty members. The top 150 schools accounted for $83.3 \%$ first job placements. We also ran a model that treated all those schools outside the top 150 as having a rank of 151 and obtained similar results. Further, we tried a model focusing on the top 150 schools and obtained similar results.
}

lower. This indicates that $\mathrm{CB}$ job candidates are disadvantaged over QT candidates with same numbers of publications and need more publications to overcome their disadvantages. To have the same placement as a QT candidate, a CB candidate needs to have one more tier- 1 or tier- 2 publication. This is consistent with the job market observation. A QT candidate with one more tier-1 or tier-2 publication could be placed in schools ranked higher by 40 and 38 positions than a $\mathrm{CB}$ candidate without publications. A CB candidate with two more tier-1, tier-2, or one tier-1 plus one tier-2 publication could be placed in schools ranked higher by 17,27 , and 22 positions than a QT candidate.

\footnotetext{
${ }^{8}$ We also tried to rank these schools by the total number of authorshipsadjusted articles published by their faculty in all tier-1 journals in the entire period covered. The ranks obtained this way are constant over time. We obtained similar results as those on time-varying school ranks.
} 
We find that publications of different tiers play very different roles in the job market. While top-tier publications serve as good signals of a candidate's research capacity and help to place him/her in a more reputable school, low-tier publications do just the opposite, sending out a negative signal about a candidate's research capability and academic ambition. This holds for both CB and QT candidates. QT candidates who have a tier-1 publication are likely to be placed in schools 17 positions higher compared with candidates who do not have any tier-1 paper. Similarly, for a CB candidate, such benefit by a tier-1 paper is 21 positions higher in school rank. One tier-2 publication is associated with 15 and 27 positions better placement for QT and CB candidates, respectively. One tier1 publication and one tier-2 publication together can boost up a QT candidate by 30 positions and a CB candidate by 45 positions. Tiered publications matter more to a $\mathrm{CB}$ job candidate than to a QT candidate. However, tier-3 publications do not help but hurt the initial job placement. One tier-3 publication can drag down a QT candidate's placement by five positions and a $\mathrm{CB}$ candidate's placement by 14 positions. Tier-3 publications hurt $\mathrm{CB}$ candidates more than QT candidates. The implication is, for job candidates, it is better not to have any publications than to have low-tier publications.

\subsection{Associate Promotion}

Promotion in academia is a mechanism to retain and recruit productive scholars. ${ }^{9}$ In many universities, publish-or-perish has become a norm, a system; therefore, academic promotions depend crucially on the quantity and quality of publications. To check how publications and citations affect researchers' likelihood to be promoted, we run a discrete time proportional hazard model [18] of getting promoted as follows:

$$
\begin{aligned}
& h_{i}\left(t, x_{t}\right)=h_{0}(t) \psi\left(x_{i t}\right) \\
& h_{0}(t)=\exp \left(\alpha_{t}\right) \\
& \psi\left(x_{i t}\right)=\exp \left(\beta_{\text {Type }, t} \text { Type }_{i} * t_{i}+\beta_{\text {Type }, \text { year } \text { Type }_{i}}{ }^{*} \text { year }+\beta_{\text {Type }} \text { Gender }^{*} \text { Type }_{i}\right.
\end{aligned}
$$

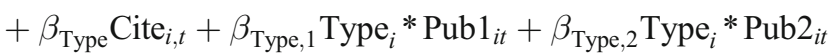

$$
\begin{aligned}
& \left.+\beta_{\text {Type }, 3} \text { Type }_{i} * \text { Pub3 }_{i t}+\beta_{\text {age }} t_{i}+\beta_{1} I_{i, \mathrm{st}}+\beta_{2} I_{i, \mathrm{PhD}}\right)
\end{aligned}
$$

where $h_{i}\left(t, x_{t}\right)$ is the hazard that researcher $i$ obtains associate promotion at academic age $t$, and $h_{0}(t)$ is the baseline hazard. We use a nonparametric specification for the baseline hazard. $\psi\left(x_{i t}\right)$ is the covariate function, $\mathrm{Cite}_{i t}$ is the cumulative citation, and $\mathrm{Pub}_{i t}, \mathrm{Pub} 2_{i t}$, and $\mathrm{Pub} 3_{i t}$ are, respectively, cumulative tier-1, tier-2, and tier-3 publications. The model results are in Table 6.

First, the hazard of getting promoted changes nonlinearly with academic age (Fig. 8a). It grows quickly up to year 6, and peaked at year 9 and then goes down. Everything else being the same, at almost all academic ages, QT researchers are significantly less likely to get promoted than CBs. Second, we found the hazard to be promoted decreases steadily along the years (Fig. 8b), which validates the observation of increasing difficulty to obtain associate promotion. Third, across both researcher types, there is no significant difference between male and female in the hazard of getting promoted. Fourth, tier-1 and tier-2 publications can significantly increase the hazard of promotion, and tier-3 publications decrease CBs chance to be promoted and have no effect on rates for associate promotion for QTs. In terms of the magnitude of the impact, one tier-1 publication weighs more than three tier-2 publications. Fifth, citations do not matter much for associate promotion, both for QTs and CBs. ${ }^{10}$ This might not be surprising because when many researchers put up their dossiers for tenure promotion, their papers are either recently published or still forthcoming. Recognizing this, schools do not put too much weight on citations.

\subsection{Full Professorship Promotion}

Another milestone in the academic career is the full professorship promotion. We run a similar discrete hazard model of full promotion since associate promotion, accounting for the effects of years since associate promotion, fixed effects for year of full promotion, citation, publications of different tiers, gender, and researcher type. The results are in Table 7.

\footnotetext{
${ }^{9}$ In most schools, associate promotion means tenure, but in some schools, tenure position is only for full professorship promotion. From their CVs, we cannot tell whether an associate promotion is with or without tenure, so we use the term "associate promotion" instead of tenure.

${ }^{10}$ To account for the uneven distribution of citation, we tried a model using logarithm of citation, and obtained similar results.
} 
Table 6 Results of discrete proportional hazard model of associate promotion

\begin{tabular}{|c|c|c|c|c|c|c|c|c|c|}
\hline \multirow[t]{2}{*}{ Academic age } & \multicolumn{2}{|l|}{$\mathrm{CB}$} & \multicolumn{2}{|l|}{ QT } & \multirow[t]{2}{*}{ Year } & \multicolumn{2}{|l|}{$\mathrm{CB}$} & \multicolumn{2}{|l|}{ QT } \\
\hline & est & se & est & se & & est & se & est & se \\
\hline 2 & -9.791 & 1.179 & -7.781 & 0.776 & 1990 & 1.737 & 0.538 & 2.329 & 0.498 \\
\hline 3 & -7.230 & 0.763 & -6.601 & 0.706 & 1991 & 2.049 & 0.474 & 1.636 & 0.607 \\
\hline 4 & -5.201 & 0.555 & -5.002 & 0.542 & 1992 & 1.756 & 0.474 & 2.741 & 0.469 \\
\hline 5 & -4.031 & 0.518 & -4.441 & 0.518 & 1993 & 1.665 & 0.475 & 2.501 & 0.475 \\
\hline 6 & -2.408 & 0.504 & -3.033 & 0.491 & 1994 & 1.096 & 0.519 & 1.751 & 0.529 \\
\hline 7 & -2.292 & 0.513 & -2.811 & 0.503 & 1995 & 1.459 & 0.497 & 1.891 & 0.506 \\
\hline 8 & -1.985 & 0.532 & -2.943 & 0.526 & 1996 & 1.867 & 0.471 & 2.536 & 0.488 \\
\hline 9 & -1.726 & 0.542 & -2.307 & 0.539 & 1997 & 1.472 & 0.493 & 1.675 & 0.547 \\
\hline 10 & -1.883 & 0.590 & -2.396 & 0.560 & 1998 & 2.208 & 0.453 & 1.615 & 0.510 \\
\hline 11 & -2.108 & 0.658 & -2.628 & 0.676 & 1999 & 1.542 & 0.505 & 2.143 & 0.458 \\
\hline 12 & -2.277 & 0.640 & -2.475 & 0.653 & 2000 & 1.801 & 0.465 & 1.051 & 0.546 \\
\hline Female & 0.060 & 0.160 & -0.087 & 0.217 & 2001 & 1.282 & 0.479 & 2.070 & 0.439 \\
\hline Total citations $/ 10$ & 0.033 & 0.026 & -0.005 & 0.017 & 2002 & 1.518 & 0.466 & 1.823 & 0.461 \\
\hline Total tier-1 publications & 0.484 & 0.040 & 0.201 & 0.062 & 2003 & 1.467 & 0.452 & 1.389 & 0.475 \\
\hline Total tier-2 publications & 0.135 & 0.043 & 0.134 & 0.071 & 2004 & 2.122 & 0.431 & 1.521 & 0.443 \\
\hline Total tier-3 publications & -0.101 & 0.046 & 0.009 & 0.068 & 2005 & 1.217 & 0.488 & 1.432 & 0.444 \\
\hline 1984 or before & -8.531 & 625.9 & -9.169 & 741 & 2006 & 1.719 & 0.430 & 1.000 & 0.454 \\
\hline 1985 & 3.392 & 0.977 & 2.875 & 1.096 & 2007 & 1.650 & 0.437 & 0.724 & 0.446 \\
\hline 1986 & 2.334 & 0.892 & -11.757 & 901 & 2008 & 1.649 & 0.435 & 0.909 & 0.418 \\
\hline 1987 & 3.254 & 0.559 & 2.521 & 0.549 & 2009 & 1.737 & 0.415 & 0.626 & 0.427 \\
\hline 1988 & 2.561 & 0.575 & 1.906 & 0.627 & 2010 & 0.460 & 0.456 & 0.512 & 0.424 \\
\hline 1989 & 2.488 & 0.523 & 2.420 & 0.540 & 2011 & 0.000 & . & 0.000 & . \\
\hline \multicolumn{10}{|l|}{ Other control variables } \\
\hline Working school fixed effect & Yes & & & & & & & & \\
\hline $\mathrm{PhD}$ school fixed effect & Yes & & & & & & & & \\
\hline$N$ & 7981 & & & & & & & & \\
\hline LL & -1201 & & & & & & & & \\
\hline
\end{tabular}

Figure 9a shows the hazard of being promoted to full professorship by years after associate promotion. For QT scholars, such rate peaks at 5 years after associate promotion and levels off afterwards. It starts to slip down at 10 years after associate promotion. For CB scholars, the hazard of promotion also peaks at 5 years after associate promotion, but there
Fig. 8 Hazard of associate promotion

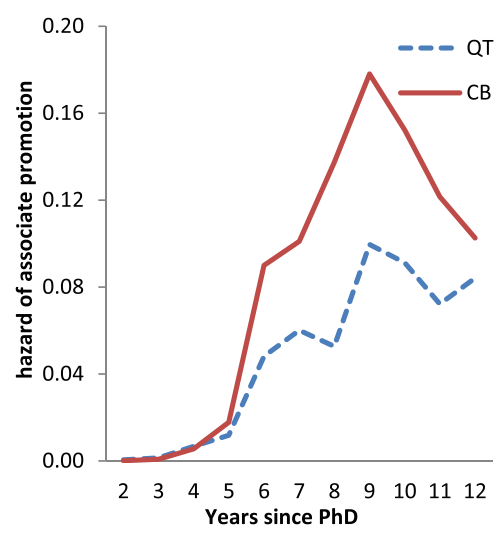

(a) By Academic Age

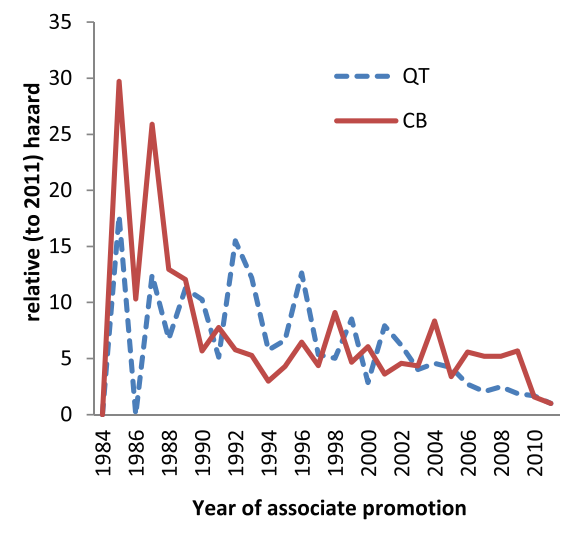

(b) Relative (to 2011) Hazard 
Table 7 Results of discrete proportional hazard model of full promotion

\begin{tabular}{|c|c|c|c|c|c|c|c|c|c|}
\hline \multirow[t]{2}{*}{ Years since associate promotion } & \multicolumn{2}{|l|}{$\mathrm{CB}$} & \multicolumn{2}{|l|}{ QT } & \multirow[t]{2}{*}{ Year } & \multicolumn{2}{|l|}{$\mathrm{CB}$} & \multicolumn{2}{|l|}{ QT } \\
\hline & est & se & est & se & & est & se & est & se \\
\hline 0 & -6.440 & 0.870 & -9.280 & 1.171 & 1989 & -10.726 & 838.400 & 2.321 & 1.740 \\
\hline 1 & -7.871 & 1.256 & -10.869 & 1.460 & 1990 & 1.434 & 1.129 & -10.284 & 728 \\
\hline 2 & -5.528 & 0.759 & -8.274 & 1.076 & 1991 & -12.239 & 599.400 & 2.641 & 1.277 \\
\hline 3 & -4.474 & 0.698 & -7.692 & 1.039 & 1992 & 0.490 & 0.687 & 2.689 & 1.044 \\
\hline 4 & -4.170 & 0.695 & -7.464 & 1.056 & 1993 & 1.357 & 0.578 & 2.722 & 0.989 \\
\hline 5 & -2.328 & 0.671 & -5.237 & 1.006 & 1994 & 0.109 & 0.728 & 2.247 & 0.942 \\
\hline 6 & -2.728 & 0.694 & -5.667 & 1.042 & 1995 & 1.434 & 0.518 & 3.189 & 0.888 \\
\hline 7 & -2.786 & 0.710 & -5.433 & 1.063 & 1996 & 0.347 & 0.625 & 2.071 & 1.006 \\
\hline 8 & -2.681 & 0.741 & -5.527 & 1.083 & 1997 & 0.980 & 0.505 & 2.809 & 0.876 \\
\hline 9 & -2.785 & 0.773 & -5.250 & 1.122 & 1998 & 1.061 & 0.505 & 2.911 & 0.861 \\
\hline 10 & -2.868 & 0.793 & -5.355 & 1.153 & 1999 & 0.784 & 0.530 & 2.344 & 0.904 \\
\hline 11 & -2.153 & 0.723 & -6.155 & 1.163 & 2000 & 1.087 & 0.481 & 3.649 & 0.869 \\
\hline 12 & -2.986 & 1.009 & -7.243 & 1.553 & 2001 & 0.723 & 0.513 & 2.642 & 0.927 \\
\hline 13 & -2.590 & 1.243 & -6.051 & 1.492 & 2002 & 0.748 & 0.521 & 3.007 & 0.884 \\
\hline Female & -0.215 & 0.244 & -0.037 & 0.404 & 2003 & 1.258 & 0.469 & 2.634 & 0.915 \\
\hline Total citations $/ 10$ & -0.009 & 0.010 & -0.034 & 0.014 & 2004 & 0.964 & 0.494 & 2.168 & 0.920 \\
\hline Total tier-1 publications & 0.279 & 0.045 & 0.195 & 0.068 & 2005 & 1.155 & 0.474 & 2.542 & 0.886 \\
\hline Total tier-2 publications & 0.223 & 0.040 & 0.080 & 0.068 & 2006 & 0.852 & 0.462 & 2.862 & 0.873 \\
\hline Total tier-3 publications & 0.038 & 0.041 & 0.011 & 0.062 & 2007 & 0.823 & 0.451 & 3.009 & 0.856 \\
\hline 1985 & 7.562 & 1.495 & -7.925 & 4915 & 2008 & 0.262 & 0.500 & 2.795 & 0.842 \\
\hline 1986 & 7.728 & 1.657 & -7.516 & 4915 & 2009 & 0.011 & 0.478 & 2.655 & 0.831 \\
\hline 1987 & -10.447 & 1343 & -8.961 & 1529 & 2010 & -0.039 & 0.443 & 2.750 & 0.799 \\
\hline 1988 & -9.859 & 1058 & -10.190 & 955 & 2011 & 0.000 & . & 0.000 & . \\
\hline \multicolumn{10}{|l|}{ Other control variables } \\
\hline Working cchool fixed effect & Yes & & & & & & & & \\
\hline $\mathrm{PhD}$ school fixed effect & Yes & & & & & & & & \\
\hline$N$ & 4619 & & & & & & & & \\
\hline LL & -798 & & & & & & & & \\
\hline
\end{tabular}

are several peaks at year 8, year 11, and year 13. Besides, QT scholars are less likely to be promoted than their $\mathrm{CB}$ counterparts at any time point. Figure $9 \mathrm{~b}$ depicts the trend of the relative (to 2011) hazard of full professorship promotion.
Fig. 9 Hazard of full professorship promotion

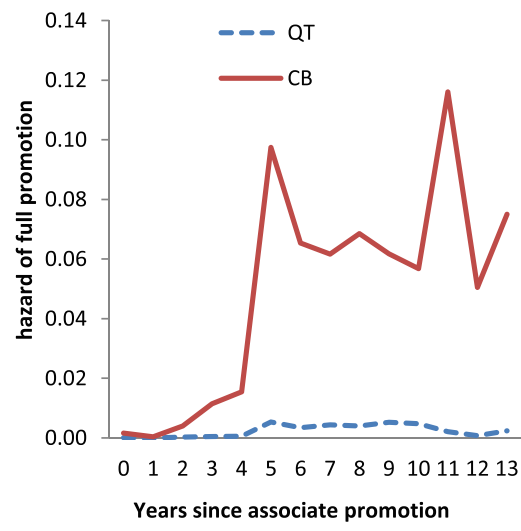

(a) By Years since Associate Promotion

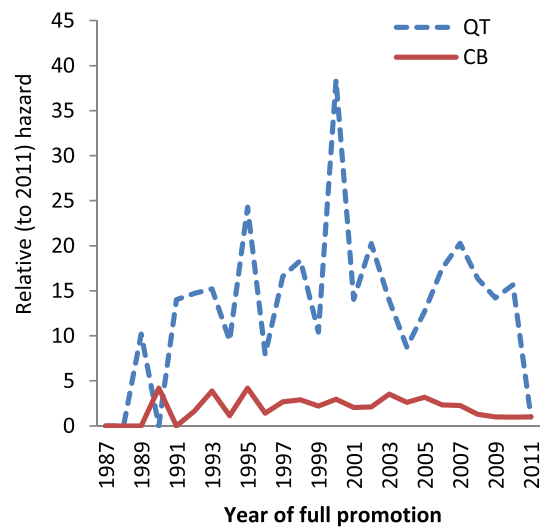

(b) Relative (to 2011) Hazard 
Interestingly, unlike associate promotion that shows a declining trend, the hazard of being promoted to full professorship for QT scholars zigzags up till 2010. For CB scholars, the hazard remains relatively stable. In almost all years, QTs have higher rates to be promoted compared to CB scholars. Such advantage outweighs greatly the slight disadvantage of full promotion by years since associate promotion, as shown in Fig. 9a.

There are no differences in the full promotion between female and male researchers. Strangely, citations lower the hazard of promotion for QTs, though the magnitude of the effect is very small. Citations do not affect the odds of full promotion for CBs. Tier-1 publications matter the most both for QTs and CBs in the full promotion, followed by tier-2 publications. Tier-3 publications have no significant impact on the full promotion.

\section{Discussions and Implications}

With business environment rapidly shifting to the virtual world, quantitative modelers are expected and destined to play an imperative role to come up with good research that inspires or assists strategic and daily marketing decisions. In this research, we collect data of all standing marketing faculties from the world's top 150 universities and investigate their research productivity and impact. Through this study, we hope to provide a better understanding of the field and offer some benchmarks that have implications for the future development of individual scholars, business schools, or the marketing field as a whole.

One finding is that the portfolio of quantitative scholars becomes more and more international. North Americans are the largest group, South Asians are the second largest group, and Chinese are one of the fastest growing groups in the field. With the rise of emerging economy and continuing trend of globalization, it will therefore be beneficial for schools to have a more intentional portfolio of its marketing faculties so that external links can be established to source talents for $\mathrm{PhD}$ program, obtain new research ideas or data, etc. In addition, we also find that despite an increasing number of non-marketing PhDs joining the marketing field, the proportion of non-marketing $\mathrm{PhDs}$ is actually decreasing. The marketing discipline has been using theories and research methods from other disciplines such as economics, psychology, statistics, transportation, etc., and has benefited and flourished from this. Doctoral graduates from other disciplines are usually equipped with the most updated knowledge and research tools in those disciplines. Hence, the joining of nonmarketing PhDs into the marketing field will not only enable the research of new marketing phenomena, but enable the study of existing and new questions from multiple perspectives, and enrich the whole discipline.

Promotion in academia is a mechanism to retain and recruit productive scholars. From this perspective, setting up a fair and rewarding mechanism is extremely important to motivate researchers. We found QT and $\mathrm{CB}$ researchers exhibit quite different patterns in research productivity. Casual observations of research output by doctoral students, job market candidates, and faculty members in marketing seem to suggest that QT researchers have fewer publications than their $\mathrm{CB}$ counterparts do. We find that $\mathrm{CB}$ researchers initially far outnumber QTs in publications and citations, and QT researchers can gradually catch up with $\mathrm{CBs}$ in tier-1 and tier-2 publications, but they always trail behind CBs in citations. When other factors of research productivity are controlled for, it takes 26 years for QT researchers to catch up with $\mathrm{CB}$ researchers in total research output of tiered publications. Difference between QTs and CBs in research productivity due to different knowledge production processes is huge. Hence, using the same bar to assess research productivity of QTs and CBs is detrimental to the development of QT scholars. This might explain the survival bias shown in the data that associate promotion is a challenge for QT scholars. However, once surviving the associate promotion, QT researchers have a much higher likelihood to be promoted to full professorship than CBs.

Our paper is not without limitations. Since it only looks at current faculty members in the top 150 schools, it suffers from a survivorship bias-only those who were hired by these schools in some point of their academic life and survived the tenure process are included in the sample. Our sample does not include the retired, the deceased, and the dropouts to lower-rank schools or industries. Since we are comparing QTs and $\mathrm{CBs}$, as long as these exclusions are not systematically different between these two subareas, our findings will still hold. A suitable correction would be to track cohorts of new doctorates over time for 20 or 30 years. However, this will take time, and the curriculum vitae of those who are no longer in academia may not be available, thus furthering concerns over survivorship bias. Nevertheless, it is worthwhile to try, and we will delve into this in our future research.

Acknowledgment This project is funded by the Singapore Ministry of Education research grant, R-316-000-086-112. 


\section{Appendices}

\section{Appendix 1}

Table 8 List of the top 50 universities

\begin{tabular}{|c|c|c|c|}
\hline No. & University & No. & University \\
\hline 1 & University of Pennsylvania & 26 & Ohio State University \\
\hline 2 & Columbia University & 27 & Tilburg University \\
\hline 3 & University of Chicago & 28 & Cornell University \\
\hline 4 & Northwestern University & 29 & University North Carolina \\
\hline 5 & Duke University & 30 & University South Carolina \\
\hline 6 & New York University & 31 & Dartmouth College \\
\hline 7 & University Florida & 32 & University of Arizona \\
\hline 8 & University South California & 33 & University of Washington \\
\hline 9 & University Michigan & 34 & University of Texas at Dallas \\
\hline 10 & University of California at Los Angeles & 35 & Washington University \\
\hline 11 & University of Texas at Austin & 36 & University of Colorado \\
\hline 12 & Stanford University & 37 & Carnegie Mellon University \\
\hline 13 & University of Wisconsin & 38 & University of Toronto \\
\hline 14 & University of Minnesota & 39 & University of British Columbia \\
\hline 15 & MIT & 40 & University of Iowa \\
\hline 16 & University of California at Berkeley & 41 & Texas A\&M University System \\
\hline 17 & Pennsylvania State University & 42 & Erasmus University \\
\hline 18 & INSEAD & 43 & London Business School \\
\hline 19 & Harvard University & 44 & South Methodist University \\
\hline 20 & Hong Kong University Science \& Technology & 45 & University of Houston \\
\hline 21 & University of Maryland & 46 & University of Cincinnati \\
\hline 22 & Arizona State University & 47 & University of Illinois at Urbana Champaign \\
\hline 23 & University of Pittsburgh & 48 & University of California at Irvine \\
\hline 24 & Yale University & 49 & Emory University \\
\hline 25 & Indiana University & 50 & Vanderbilt University \\
\hline
\end{tabular}

Appendix 2

Table 9 List of tier-1 journals in the four areas published in by marketing faculty

\begin{tabular}{|c|c|c|c|c|c|}
\hline Journal & Type & $\%$ Pubs & Journal & Type & $\%$ Pubs \\
\hline Journal of Marketing Research & BIZ & 9.95 & Journal of International Economics & ECON & 0.01 \\
\hline Journal of Consumer Research & BIZ & 9.25 & Journal of Accounting \& Economics & ECON & 0.01 \\
\hline Marketing Science & BIZ & 6.44 & Journal of Public Economics & ECON & 0.01 \\
\hline Journal of Marketing & BIZ & 5.20 & Real Estate Economics & ECON & 0.01 \\
\hline Management Science & BIZ & 3.28 & Journal of Monetary Economics & ECON & 0.01 \\
\hline Journal of Business & $\mathrm{BIZ}$ & 0.34 & Journal of Urban Economics & ECON & 0.01 \\
\hline Strategic Management Journal & $\mathrm{BIZ}$ & 0.31 & Journal of Labor Economics & ECON & 0.00 \\
\hline Operations Research & BIZ & 0.25 & Pharmacoeconomics & ECON & 0.00 \\
\hline Academy of Management Journal & $\mathrm{BIZ}$ & 0.15 & Journal of Real Estate Finance \& Economics & ECON & 0.00 \\
\hline Organization Science & BIZ & 0.09 & Journal of Personality \& Social Psychology & PSYCH & 1.74 \\
\hline Academy of Management Review & BIZ & 0.05 & Psychological Science & PSYCH & 0.86 \\
\hline
\end{tabular}


Table 9 (continued)

\begin{tabular}{|c|c|c|c|c|c|}
\hline Journal & Type & $\%$ Pubs & Journal & Type & $\%$ Pubs \\
\hline MIS Quarterly & $\mathrm{BIZ}$ & 0.05 & Journal of Applied Psychology & PSYCH & 0.41 \\
\hline Journal of Finance & $\mathrm{BIZ}$ & 0.02 & Journal of Experimental Psychology: General & PSYCH & 0.22 \\
\hline Accounting Review & $\mathrm{BIZ}$ & 0.02 & Journal of Experimental Psychology: Applied & PSYCH & 0.16 \\
\hline Journal of Money, Credit \& Banking & $\mathrm{BIZ}$ & 0.02 & Psychological Bulletin & PSYCH & 0.15 \\
\hline Journal of the Operational Research Society & $\mathrm{BIZ}$ & 0.05 & Annual Review of Psychology & PSYCH & 0.10 \\
\hline Manufacturing \& Service Operations Management & $\mathrm{BIZ}$ & 0.07 & Psychological Review & PSYCH & 0.09 \\
\hline Organizational Behavior \& Human Decision Processes & $\mathrm{BIZ}$ & 1.07 & $\begin{array}{l}\text { Journal of Experimental Psychology: Human } \\
\text { Perception \& Performance }\end{array}$ & PSYCH & 0.07 \\
\hline Journal of Financial Economics & $\mathrm{BIZ}$ & 0.01 & Health Psychology & PSYCH & 0.05 \\
\hline Contemporary Accounting Research & BIZ & 0.01 & Perception \& Psychophysics & PSYCH & 0.04 \\
\hline Review of Financial Studies & $\mathrm{BIZ}$ & 0.01 & Cognition & PSYCH & 0.03 \\
\hline Journal of Financial \& Quantitative Analysis & BIZ & 0.01 & Personnel Psychology & PSYCH & 0.02 \\
\hline Journal of Accounting Research & $\mathrm{BIZ}$ & 0.01 & Journal of Cognitive Neuroscience & PSYCH & 0.00 \\
\hline Journal of Human Resources & $\mathrm{BIZ}$ & 0.00 & Neuropsychologia & PSYCH & 0.00 \\
\hline Journal of Real Estate Research & $\mathrm{BIZ}$ & 0.00 & Journal of the American Statistical Association & STAT & 0.18 \\
\hline Rand Journal of Economics & $\mathrm{ECON}$ & 0.19 & Review of Economics \& Statistics & STAT & 0.06 \\
\hline American Economic Review & ECON & 0.16 & Journal of Computational \& Graphical Statistics & STAT & 0.02 \\
\hline Journal of Economic Theory & $\mathrm{ECON}$ & 0.09 & Statistical Science & STAT & 0.02 \\
\hline Games \& Economic Behavior & $\mathrm{ECON}$ & 0.08 & Statistics \& Computing & STAT & 0.01 \\
\hline Quarterly Journal of Economics & $\mathrm{ECON}$ & 0.05 & Annals of Statistics & STAT & 0.01 \\
\hline Information Economics \& Policy & ECON & 0.04 & Annals of Applied Statistics & STAT & 0.01 \\
\hline Journal of Political Economy & $\mathrm{ECON}$ & 0.04 & Journal of the Royal Statistical Society Series A & STAT & 0.01 \\
\hline Journal of Law \& Economics & ECON & 0.04 & Journal of the Royal Statistical Society Series B & STAT & 0.00 \\
\hline Econometrica & $\mathrm{ECON}$ & 0.03 & Journal of the Royal Statistical Society Series C & STAT & 0.02 \\
\hline Review of Economic Studies & ECON & 0.03 & Advances In Applied Probability & STAT & 0.00 \\
\hline
\end{tabular}

\section{References}

1. Chu, Junhong. 2014. Cumulative advantage of research productivity: how large is it and who has it? Working paper, NUS Business School

2. Cole S (1979) Age and scientific performance. Am J Sociol 84:958977

3. Eaton JP, Ward JC, Jumar A, Reingen PH (1999) Structural analysis of co-author relationships and author productivity in selected outlets for consumer behavior research. J Consum Psychol 8(1):39-59

4. Grewal R, Dearden JA, Lilien GL (2008) The university rankings game: modeling the competition among universities for ranking. Am Stat 62(3): 1-6

5. Gupta BM, Kumar S, Aggarwal BS (1999) A comparison of productivity of male and female scientists of CSIR. Scientometrics 45(2): 269-289

6. Lehmann DR (2005) Journal evolution and the development of marketing. J Publ Policy Mark 24:137-142

7. Levin SG, Stephan PE (1991) Research productivity over the life cycle: Evidence for academic scientists. Am Econ Rev 81(1):114-132

8. Long JS, McGinnis R (1981) Organizational context and scientific productivity. Am Sociol Rev 46:422-442
9. Long JS (1978) Productivity and academic position in the scientific career. Am Sociol Rev 43:889-908

10. Long JS (1992) Measures of sex differences in scientific productivity. Soc Forces 71(1):159-178

11. Lotka AJ (1926) The frequency distribution of scientific productivity. J Wash Acad Sci 16(12):317-324

12. McAlister L (2005) Unleashing potential. J Mark 69:16-17

13. Merton RK (1968) The Matthew e in science. Sci New Ser 159(3810): 56-63

14. Mittal V, Feick L, Murshed F (2008) Publish and prosper: the financial impact of publishing by marketing faculty. Mark Sci 27(3):430-442

15. Park SH, Gordon ME (1996) Publication records and tenure decisions in the field of strategic management. Strateg Manag J 17(2): $109-128$

16. Prpic K (1996) Characteristics and determinants of eminent scientists' productivity. Scientometrics 36(2):185-206

17. Rogers RC, Maranto CL (1989) Causal models of publishing productivity in psychology. J Appl Psychol 74(4):636-649

18. Seetharaman PB, Chintagunta PK (2003) The proportional hazard model for purchase timing: a comparison of alternative specifications. J Bus Econ Stat 21(3):368-382

19. Seggie SH, Griffith DA (2009) What does it take to get promoted in marketing academia? Understanding exceptional 
publication productivity in the leading marketing journals. $\mathrm{J}$ Mark 73:122-132

20. Stremersch S, Verniers I, Verhoef PC (2007) The quest for citations: drivers of article impact. J Mark 71:171-193

21. Stevenson, Adlia E. (1952), Speech, Richmond, Virginia, 20 September 1952

22. Talukdar D, Hariharan VG, Boo C (2011) Empirical regularity in academic research productivity patterns in marketing. Int J Res Mark 28(3):248-257
23. Tellis GJ, Kandy RK, Ackerman DS (1999) In search of diversity: the record of major marketing journals. J Mark Res 36:120-131

24. Williamson IO, Cable DM (2003) Predicting early career research productivity: the case of management faculty. J Organ Behav 24(1): 25-44

25. Zamudio C, Wang Y, Haruvy E (2011) The job market for assistant professors in marketing. Working paper, University of Texas at Dallas 